\title{
Improved Corrosion Behavior of AZ31 Alloy through ECAP Processing
}

\author{
A. I. Alateyah ${ }^{1, *}$, Talal A. Aljohani ${ }^{2, *}$, Majed O. Alawad $\left.{ }^{3}{ }^{(}\right)$, H. Abd El-Hafez ${ }^{1,4}{ }^{\oplus}$, A. N. Almutairi ${ }^{1}$, \\ E. S. Alharbi ${ }^{1}$, R. Alhamada ${ }^{1}$, B. W. El-Garaihy ${ }^{5}$ and W. H. El-Garaihy ${ }^{1,6}{ }^{\mathbb{C}}$
}

1 Mechanical Engineering Department, College of Engineering-Unaizah, Qassim University, Unaizah 51911, Saudi Arabia; HM.Ahmed@qu.edu.sa (H.A.E.-H.); Almutairi.abdullrahman@gmail.com (A.N.A.); Eng.Eid.SAlharbi@gmail.com (E.S.A.); Rowadyousef@gmail.com (R.A.); W.Nasr@qu.edu.sa (W.H.E.-G.)

2 National Centre for Corrosion Technology, King Abdulaziz City for Science and Technology (KACST), Riyadh 11442, Saudi Arabia

3 Materials Science Research Institute, King Abdulaziz City for Science and Technology (KACST), Riyadh 11442, Saudi Arabia; moalawad@kacst.edu.sa

4 Production Engineering and Mechanical Design Department, Faculty of Engineering, Port-Said University, Port-Said 42523, Egypt

5 Mechanical Engineering Department, The American University in Cairo (AUC), Cairo 11835, Egypt; basselwgarihy@aucegypt.edu

6 Mechanical Engineering Department, Faculty of Engineering, Suez Canal University, Ismailia 41522, Egypt

* Correspondence: a.alateyah@qu.edu.sa (A.I.A.); taljohani@kacst.edu.sa (T.A.A.); Tel.: +966-055-313-3322 (A.I.A.)

check for updates

Citation: Alateyah, A.I.; Aljohani, T.A.; Alawad, M.O.; El-Hafez, H.A.; Almutairi, A.N.; Alharbi, E.S.; Alhamada, R.; El-Garaihy, B.W.; El-Garaihy, W.H. Improved Corrosion Behavior of AZ31 Alloy through ECAP Processing. Metals 2021, 11, 363. https://doi.org/10.3390/ met11020363

Academic Editor: Sebastian Feliú, Jr.

Received: 31 January 2021

Accepted: 19 February 2021

Published: 21 February 2021

Publisher's Note: MDPI stays neutral with regard to jurisdictional claims in published maps and institutional affiliations.

Copyright: (c) 2021 by the authors. Licensee MDPI, Basel, Switzerland. This article is an open access article distributed under the terms and conditions of the Creative Commons Attribution (CC BY) license (https:/ / creativecommons.org/licenses/by/ $4.0 /)$.

\begin{abstract}
This study aims to establish the effects of equal channel angular pressing (ECAP) processing on the corrosion behavior and hardness values of the AZ31 Mg alloy. The AZ31 billets were processed through ECAP successfully at $250{ }^{\circ} \mathrm{C}$ and their microstructural evolution was studied using optical and field emission scanning electron microscopy. The corrosion resistance of the AZ31 alloy was studied before and after processing through ECAP. The homogeneity of the hardness distribution was studied using both sections cut parallel and perpendicular to the extrusion direction. ECAP processing resulted in highly deformed central regions with elongated grains aligned parallel to the extrusion direction, whereas the peripheral regions showed an ultra-fine-grain recrystallized structure. After processing, small ultra-fine secondary particles were found to be homogeneously dispersed alongside the grain boundaries of the $\alpha$-Mg matrix. Regarding the corrosion properties, measurements showed that ECAP processing through 1-P and 2-Bc resulted in decreasing their corrosion rate to $67.7 \%$ and $78.3 \%$, respectively, of their as-annealed counterpart's. The corrosion resistance of the ECAPed Mg alloy increased with the number of processing passes. This was due to the refinement of the grain size of the $\alpha-\mathrm{Mg}$ matrix and secondary phases till ultra-fine size, caused by the accumulation of strain during processing. On the other hand, ECAP processing through 2-Bc resulted in increasing the Vickers hardness values by $132 \%$ and $71.8 \%$ at the peripheral and central areas, respectively, compared to the as-annealed counterpart.
\end{abstract}

Keywords: Mg alloys; corrosion behavior; Tafel plots; electrochemical impedance spectroscopy; ECAP; ultrafine-grained; severe plastic deformation

\section{Introduction}

Among the metallic materials, magnesium $(\mathrm{Mg})$ excels and shows prospects of great future success when it comes to usage in medical implants. Mg's elastic modulus is similar to that of the human bone, which naturally makes magnesium a great choice for bone implants without affecting the human structure's strength [1-3]. On top of that, $\mathrm{Mg}$ alloys are known for being biodegradable, biocompatible, and non-toxic to the human body. Their excelling in these properties has caused scientists who work with medical implants applications like osteosynthesis and cardiovascular surgery to delve into the usage of $\mathrm{Mg}$ 
alloys in these applications [4,5]. Recent technologies proposed biocompatible, non-toxic, and biodegradable materials, as they degrade continuously in the human body and are absorbed by the body during bone or tissue healing. This makes Mg alloys suitable for medical implants [4,6]. Mg also has a multitude of beneficial properties that make $\mathrm{Mg}$ alloy great candidates for industrial applications: $\mathrm{Mg}$ is the lightest metallic element, and $\mathrm{Mg}$ alloys have low densities, high strength-to-weight ratios, can be machined relatively easy, and are great dampeners [7-9]. These properties provide magnesium with a wide range of possible applications including usage in the electronics, automotive, telecommunication, military, biomedical, and aeronautical industries [8-13]. However, $\mathrm{Mg}$ alloys are not the perfect industrial material, they possess several undesirable properties that must be treated to promote the industrial usage of $\mathrm{Mg}$ alloys $[6,8,9,13,14]$. The major drawback to the industrial usage of $\mathrm{Mg}$ alloys is their poor corrosion resistance. $\mathrm{Mg}$ alloys corrode rapidly in most environments, causing electrochemical reactions, due to their low standard electrode potential $[6,10,12,15,16]$. As a result, the corrosion behavior of $\mathrm{Mg}$ alloys has been under great scrutiny in an effort to improve them [11].

To be able to utilize Mg alloys effectively, it is necessary to address their shortcomings, namely, the poor corrosion resistance, and to improve their mechanical properties. A tried and effective approach to enhance their properties is adding alloying elements, whereas another approach is processing [13,17]. A better alternative to conventional $\mathrm{Mg}$ alloys is $\mathrm{Mg}-\mathrm{Al}-\mathrm{Zn}$ alloys (AZxx). Both newly introduced elements bring to the table a lot of improvement on their own and in both facets: mechanical properties and corrosion resistance. The newly introduced alloy elements produce a passive layer that improves the alloy's corrosion resistance, as well as enhances its mechanical properties through solution strengthening $[15,18]$. Zinc (Zn) possesses a higher corrosion potential than $\mathrm{Mg}$, and thus is suitable for improving Mg alloys' corrosion resistance [1,19], while adding aluminum (Al) resulted in a significant improvement in the mechanical properties and ductility $[9,20]$. On the other end of the spectrum, the other way to improve Mg alloys' properties is through processing through severe-plastic deformation (SPD) methods, which causes grain refinement [21-23]. SPD's effect on corrosion behavior of metallic materials, like the aforementioned alloy, is notable and has been a subject of contemporary analysis [11]. Building on this, SPD processes are acclaimed for their effectiveness in enhancing the mechanical properties of $\mathrm{Mg}$ alloys as well as the corrosion resistance as highlighted before. This is due to the significant grain refinement that occurs because of the homogenization of the nano-sized second phases' distribution $[1,13,17,24]$. SPD methods' results are exemplary when it comes to the grain refinement of hardly deformable, hexagonal, close-packed crystal structures such as Mg alloys, especially for industrial applications [1,3,8,11,25]. Equal channel angular pressing (ECAP), a branch of the SPD tree, is a popular choice in the preparation of high-performance Mg alloys. ECAP-processed (ECAPed) alloys show enhancement in terms of physical-mechanical properties, (like ductility, strength, impact toughness, strain super plasticity, and corrosion resistance) $[8,12,13,26]$, which is due to the effectiveness of ECAP in preparing ultrafine-grained (UFG) metallic materials $[8,19,25-28]$.

The effects of using ECAP to process Mg alloys are well researched, with numerous studies choosing to focus on the resulting changes in mechanical properties or texture evolution. ECAP is one of the most useful methods to improve the mechanical properties as well as corrosion resistance in Mg alloys. This is a result of the superior UFG structure that results from shifting the corrosion mode. ECAP spreads the corrosion mode from localized pitting, as in the as-received sample, to a more uniform mode. This results in mitigated localized attacks with less impact on the integrity of the Mg alloys samples; this shifting is attributed to the homogenization of the distribution of the nano-sized secondary phases [17]. A number of studies substantiate these claims of ECAP's effectiveness. Li et al. [11] analyzed the influence grain refinement and second-phase redistribution on the corrosion behavior of the ZK60 alloy. Their findings proved that the ECAPed ZK60 alloys had higher corrosion current density $\left(\mathrm{I}_{\text {corr }}\right)$ on polarization curves than their as-annealed counterparts. They have also discovered that, first, a higher number of ECAP passes 
correlates with lower corrosion potential ( $\left.\mathrm{E}_{\mathrm{corr}}\right)$. Second, they found that ECAP processing mitigated any signs of localized corrosion because ECAPing results in the homogenous distribution of anodic and cathodic sites on the fine-grained alloy, and thus prevents the formation of a potential gradient across the surface of the sample. Cubides et al. [13] investigated the AZ91 alloy and the effect of ECAP processing on the microstructure evolution; they found that alloy's mechanical properties and corrosion resistance improved afterwards. The improvement in corrosion resistance can be attributed to the passivity effect, the development of an adherent and compact layer of corrosion products, and the uniformity of corrosion distribution along the surface along with the formation of shallow corrosion pits. Another study by Němec et al. [1] investigated two alloys: Mg-6 $w t \% Z n$ and Mg-12 wt $\% \mathrm{Zn}$ and the effects of ECAPing them with applied back-pressure. They discovered that the ECAPed samples had higher corrosion rates than those of the as-received samples. They also found out that the corrosion did not propagate any further in any of the material. Zhang et al. [6] conducted a study into the ECAPing of Mg-Gd-Nd$\mathrm{Zn}-\mathrm{Zr}$ alloy and its effect on the texture and microstructure. They found out that the texture became stronger and the microstructure became more refined, decreasing the corrosion rates. A study conducted into the $\mathrm{Mg}-\mathrm{Zn}$ binary alloy by Torabi et al. [29] investigated the effect of increasing $\mathrm{Zn}$ content by $\mathrm{wt} \%$; they found that increasing the Zn content up to $3 \mathrm{wt} \%$ resulted in increased corrosion resistance in the alloy but increasing it beyond that led to the increase of the corrosion rate. Torabi et al. [3] also investigated several binary magnesium-hydroxyapatite bio-nano-composites and their corrosion behaviors. The testing results proved that best alloy in terms of corrosion resistance is the $\mathrm{Mg}-5 \mathrm{HA}$. The study also found that any increase in the HA content beyond $5 \mathrm{wt} \%$ led to an increase in corrosion rate. Another study on ECAP by Prithivirajan et al. [10] investigated ECAP's influence on the corrosion behavior of the ZE41 Mg alloy. The study found that ECAPing the sample improved its grain refinement. Observing the sample's crystallographic orientation through EBSD proved that the corrosion resistance was indeed improved after using ECAP. On the other hand, a study conducted by Vaughan et al. [30] showed that ECAP has a detrimental effect on the corrosion resistance of $\mathrm{Mg}-6 \mathrm{Zn}-0.6 \mathrm{Zr}-0.4 \mathrm{Ag}-0.2 \mathrm{Ca}$ alloys. They attributed this deterioration in corrosion resistance to the formation of heterogeneous, anodic shear zones, which contained dense regions of refined grains and fine precipitates in the alloy, after using ECAP.

The current study aims to provide a detailed analysis of the effect of ECAP processing on corrosion behavior, microstructural evolution, and hardness values of the AZ31 Mg alloy. The morphologies of the AZ31 alloy and the electrochemical response were comparatively analyzed before and after processing through ECAP. To this aim, electrochemical measurements such as open circuit potential, potentiodynamic polarization, cyclic potentiodynamic polarization, and electrochemical impedance spectroscopy tests were used to examine the effects of ECAP processing on the corrosion properties. The as-annealed AZ31 alloy sample has also been tested as reference. Scanning electron microscopy was used to investigate the microstructural evolution before and after corrosion tests. To obtain better visualization, hardness contour maps along and perpendicular to the extrusion direction in new 3-D plots were created to investigate the effects of ECAP processing on the hardness distribution homogeneity across the ECAPed longitudinal and transverse sections. Finally, the interrelations between the corrosion findings, microstructural behaviors, and microhardness as a function of the number of ECAP passes were investigated. The displayed results established ECAP as an effective SPD tool for usage in the grain refinement of AZ31 alloy. Processing through ECAP resulted in superior corrosion resistance in the AZ31 alloy, making it a strong candidate for usage as a structural material in industrial applications.

\section{Materials and Methods}

Commercial AZ31 wrought alloy with a chemical composition of $2.8 \mathrm{wt} \% \mathrm{Al}, 1.2 \mathrm{wt} \%$ $\mathrm{Zn}, 0.3 \mathrm{wt} \% \mathrm{Mn}$, and $0.1 \mathrm{wt} \% \mathrm{Si}$ (balance Mg) (China Jingan Chemicals \& Alloy Limited, Shanghai, China) was ECAP processed through 1 pass (1-P) and 2 passes of route Bc (2-Bc) 
at $250{ }^{\circ} \mathrm{C}$ (by rotating the sample in the same direction along their longitudinal axis by $90^{\circ}$ before each new pass). The AZ31 bars were received with $20 \mathrm{~mm}$ diameter and $50 \mathrm{~cm}$ length. The starting extruded bars were machined into billets with a diameter of $20 \mathrm{~mm}$ and a length of $50 \mathrm{~mm}$. As it is illustrated in Figure 1, the adopted ECAP die had two cylindrical channels intersecting at an angle of $90^{\circ}$ and with an outer arc of curvature of $20^{\circ}$, supplying an equivalent strain of 1.05 on each pass in accordance with [31]. To homogenize the microstructure before any experiments could be conducted, the samples were annealed at $430{ }^{\circ} \mathrm{C}$ for $16 \mathrm{~h}$ followed by furnace cooling. The billets were pressed into the ECAP die with a speed of $10 \mathrm{~mm} / \mathrm{min}$ using graphite-based lubricant.

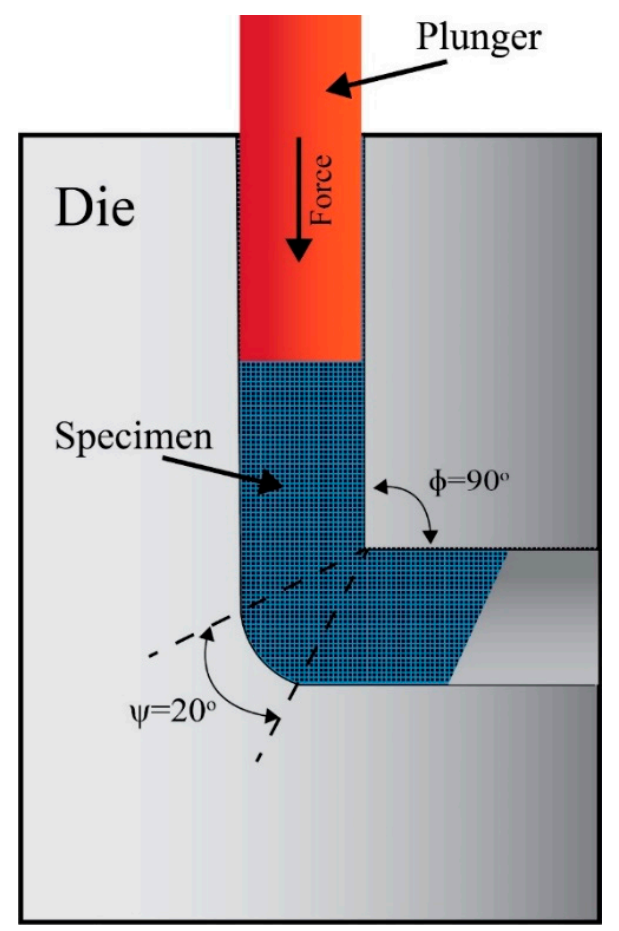

Figure 1. The schematic of the equal channel angular pressing (ECAP) die.

To characterize the microstructural evolution, an as-annealed alloy and ECAP-processed billets were used. Samples were cut along their longitudinal cross-section, and grinded, polished, and etched in a solution of $6 \mathrm{~g}$ picric acid, $5 \mathrm{~mL}$ acetic acid $(95 \%), 10 \mathrm{~mL}$ water, and $100 \mathrm{~mL}$ ethanol for $50 \mathrm{~s}$ (according to ASTM, E407-07). The microstructural evolution of the AZ31 billets before and after ECAP processing was characterized using an optical microscopy (OM) (Qualitest, Nisku, Canada), which was equipped with Vision Lite \& PE 8.0 advanced image analysis software (Clemex Technologies Inc., Vision Lite \& PE 8.0, Longueuil, Canada) and a scanning electron microscope (SEM) of type JSM-IT300 InTouchScope ${ }^{\mathrm{TM}}$ in combination with an X-MaxN Oxford energy dispersive X-ray spectroscopy EDS analyzer (Joel Ltd., Tokyo, Japan).

The Microhardness testing was conducted on both ECAP-processed and non-processed samples. To prepare them for testing, the samples were cut longitudinally and transversely and both sections were cut near the top edge of the samples. The testing was conducted on both sections to evaluate the hardness variation across the ECAPed rods' different orientations. They were then grinded and polished thoroughly to a mirror-like surface. Vickers microhardness tests (Hv) were conducted using digital microhardness tester QV1000 (Qualitest, Nisku, Canada), which was equipped with iVision_ V.1.0.0 Hv software (Clemex Technologies Inc., Longueuil, Canada), and readings were taken in a rectilinear grid-like pattern. Each microhardness indentation had $1 \mathrm{~mm}$ space between it and the next indentation. The indentation process started at the peripheries, moving towards the center. The testing was conducted on the longitudinal section (LS), which was a square $20 \times 20 \mathrm{~mm}^{2}$, 
and on the transverse section (TS), which was a circular area with diameter $20 \mathrm{~mm}$. The hardness test was conducted using a load of $1 \mathrm{~kg}$ applied for $15 \mathrm{~s}$ at a time. The results collected and displayed are the average of at least 5 indentations, all equidistant. Furthermore, color-coded maps of hardness profiles and homogeneity were used herein as visual aids to illustrate the hardness distribution along both directions.

The corrosion testing of the AZ31 samples took place using a 3-electrode flat corrosion cell. A platinum mesh was used as the counter electrode, a saturated calomel electrode (SCE), as a reference electrode, and the AZ31, as a working electrode. A Luggin capillary was used in this experiment to minimize the ohmic drop and ensure accurate results. The electrolyte used as a corrosive agent was ringer acetate $\left(130 \mathrm{mmol} / \mathrm{L}\right.$ of Na${ }^{+}, 112 \mathrm{mmol} / \mathrm{L}$ of $\mathrm{Cl}^{-}, 27 \mathrm{mmol} / \mathrm{L}$ of acetate $\left(\mathrm{C}_{3} \mathrm{H}_{6} \mathrm{O}_{3}\right), 4 \mathrm{mmol} / \mathrm{L}$ of $\mathrm{K}^{+}$, and $1.4 \mathrm{mmol} / \mathrm{L}$ of $\left.\mathrm{Ca}^{2+}\right)$ at room temperature. The experiment was conducted, and the measurements were recorded through an SP-200 Potentiostat (Bio-Logic) (Lambda System Kreft Barszczewski Sp.J., Warszawa, Poland). The potential scan rate for the polarization technique was 0.166 $\mathrm{mVs}^{-1}$ to ensure a steady-state condition. A linear potentiodynamic polarization scan was applied in a wide potential window of $\pm 250 \mathrm{mV}$ vs. open circuit potential. The electrochemical impedance spectroscopy (EIS) was performed at the open-circuit potential, $\mathrm{E}_{\mathrm{corr}}$, by applying a sinusoidal voltage between $\pm 10 \mathrm{mV}$ within a frequency range of $10 \mathrm{mHz}$ to $100 \mathrm{kHz}$. In addition, full cyclic potentiodynamic polarization was applied to investigate the development of passive layers and localized corrosion occurrence. Before performing electrochemical measurement, samples kept in the solution until the open circuit potential reach a steady state (normally about $2 \mathrm{~h}$ ).

\section{Results and Discussion}

\subsection{Microstructural Evolution}

The optical microstructure of AZ31 alloy is shown in Figure 2, the figure shows the alloy in its as-annealed condition (AA), after processing through 1-P, and after processing via 2-Bc. In addition, Figure 3 shows the microstructures of the AA, 1-P, and 2-Bc ECAPed AZ31 samples as examined by SEM. As confirmed by Figure 2a, the grain boundaries almost disappear after annealing and the microstructure of the AA sample contains large equiaxed grains of the $\alpha-\mathrm{Mg}$ matrix (approximately between 30 and $50 \mu \mathrm{m}$ in diameter) in some areas. These grains are coupled with large secondary phases which were found at the grain boundaries (GBs) (Figures 2b and 3a,b) The microstructure of AZ31 changes after processing the alloys through ECAP, and the second phases' size and the grain size diminished visibly, when compared to the AA alloy. From the microstructure, two parts can be distinguished: coarse grain (CG) $\alpha-\mathrm{Mg}$ isolated by deformation networks with the presence of UFGs nucleated along the grain, and twin boundaries occurring through dynamic recrystallization (DRX), which agreed with [10,32-34]. It can be deduced that the deformation and grain refinement begin at the GBs of the AZ31 Mg alloy and then propagate elsewhere, because the boundaries of large grains visibly contain extremely fine grains (Figure 2c) [1,15]. A considerable decrease in the alloy's grain size was caused by lattice defect generation from the SPD and DRX, too [1]. The microstructure of the $\alpha-\mathrm{Mg}$ matrix, when processed through 1-P, contains large grains (about $25 \mu \mathrm{m}$ ) coupled with finer grains $(\sim 10 \mu \mathrm{m})$ as a result of incomplete DRX with fine secondary phase particles, highlighted at both the GBs and grains interior in Figures $2 \mathrm{~d}$ and $3 \mathrm{c}, \mathrm{d}$. 


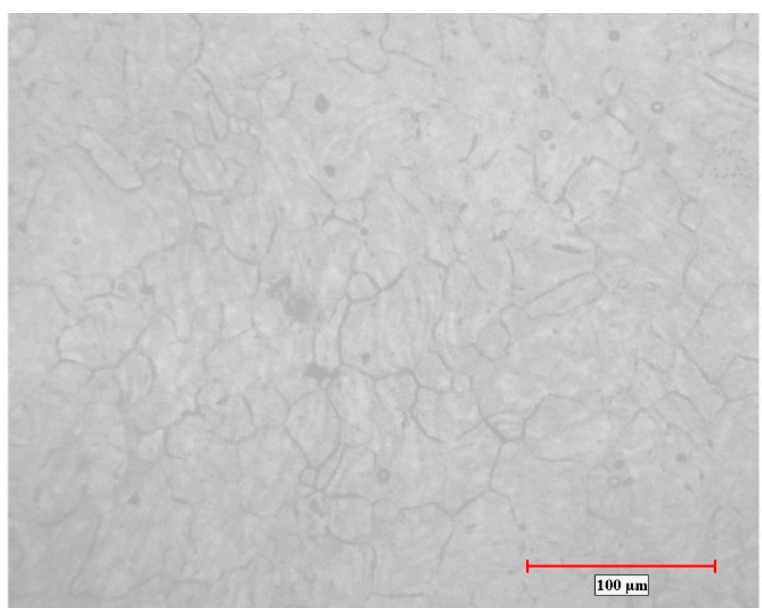

(a)

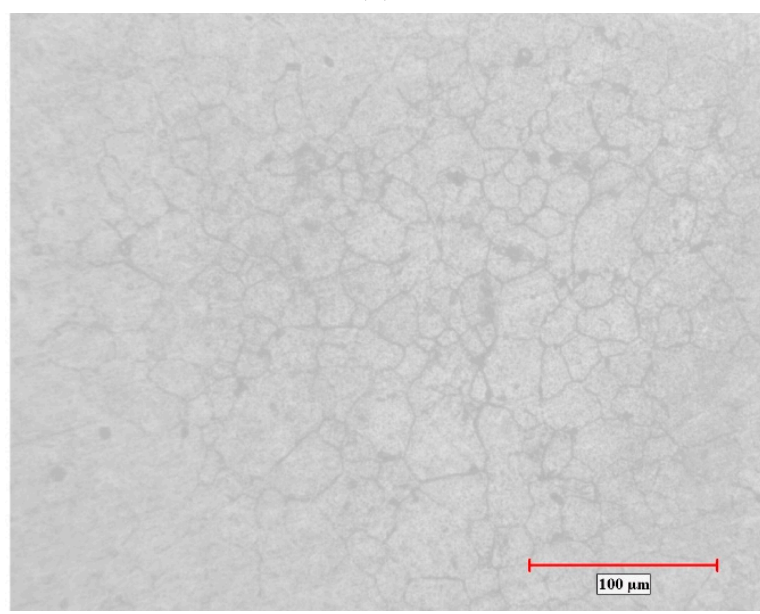

(c)

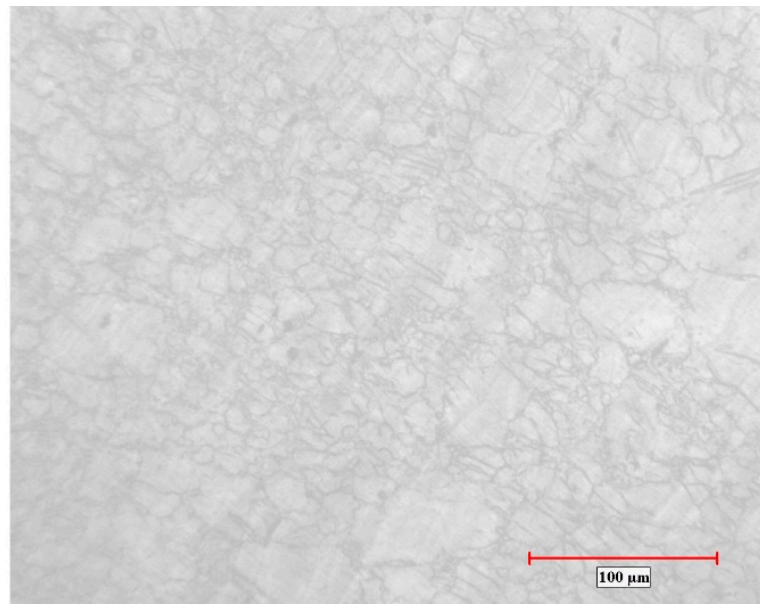

(e)

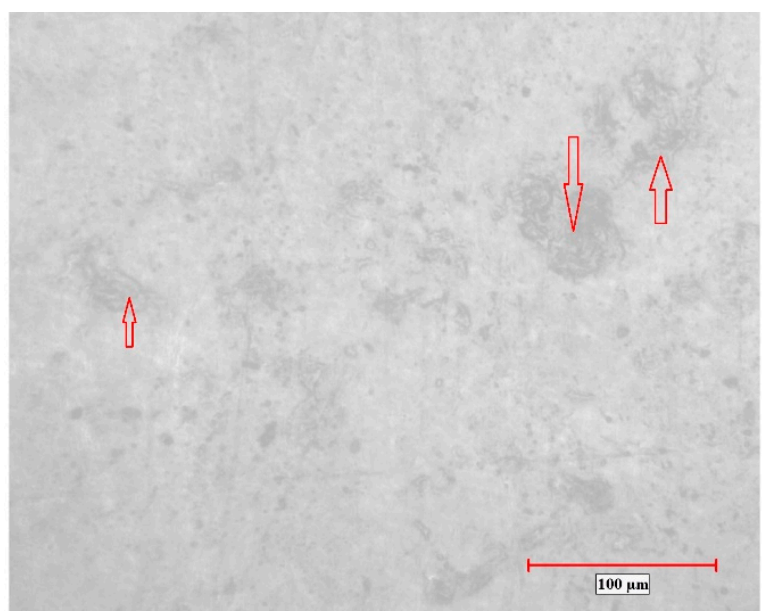

(b)

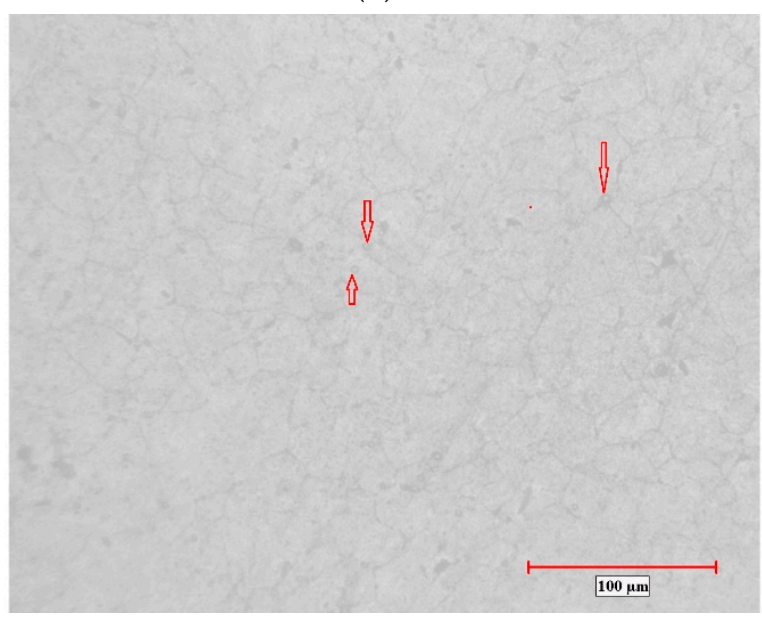

(d)

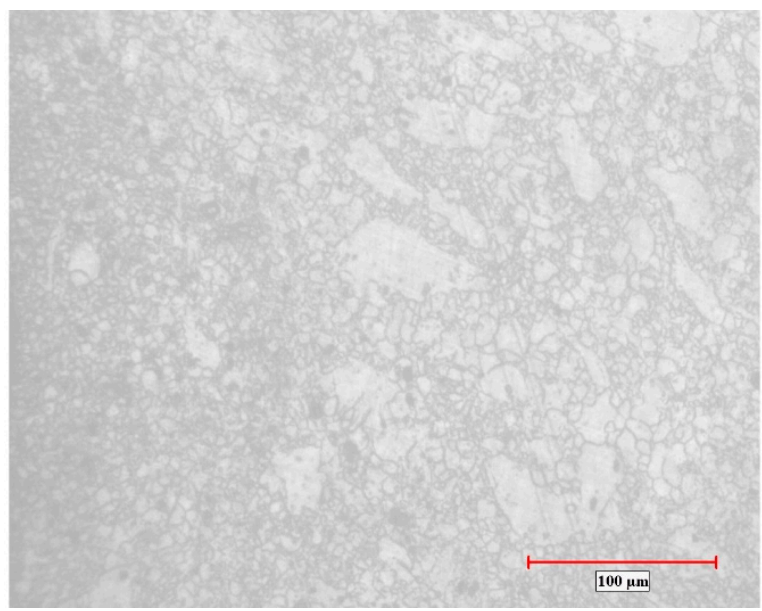

(f)

Figure 2. Optical microscopy $(\mathrm{OM})$ micrographs of the AZ31 alloy after ECAP processing (a,b) as-annealed condition (AA), (c) ECAP processed through 1 pass (1-P), and (e,f) 2 passes of route $\mathrm{Bc}(2-\mathrm{Bc})$ (arrows indicate the secondary phase particles). 


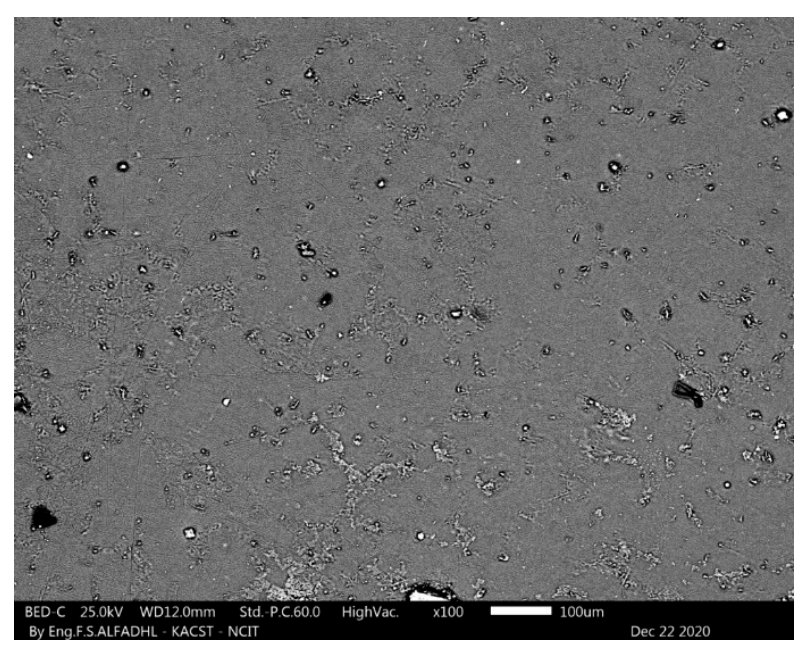

(a)

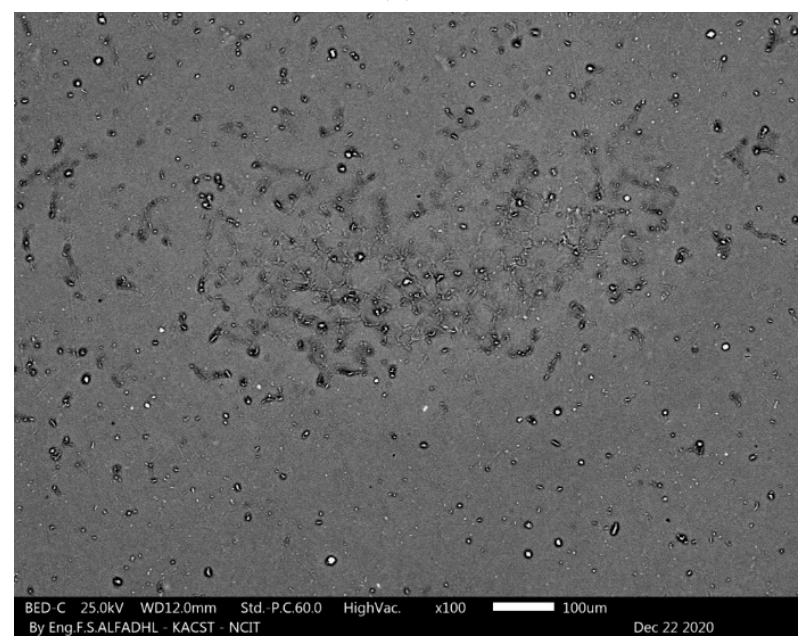

(c)

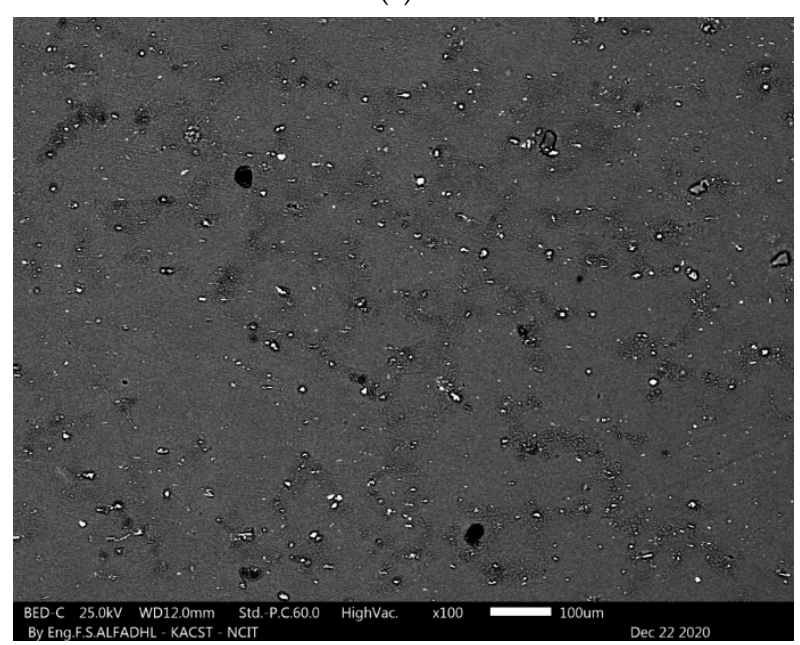

(e)

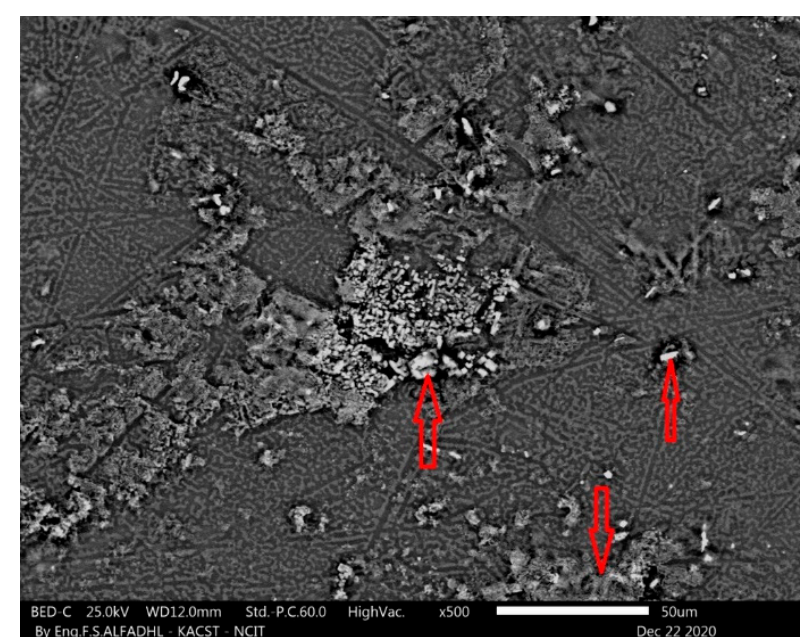

(b)

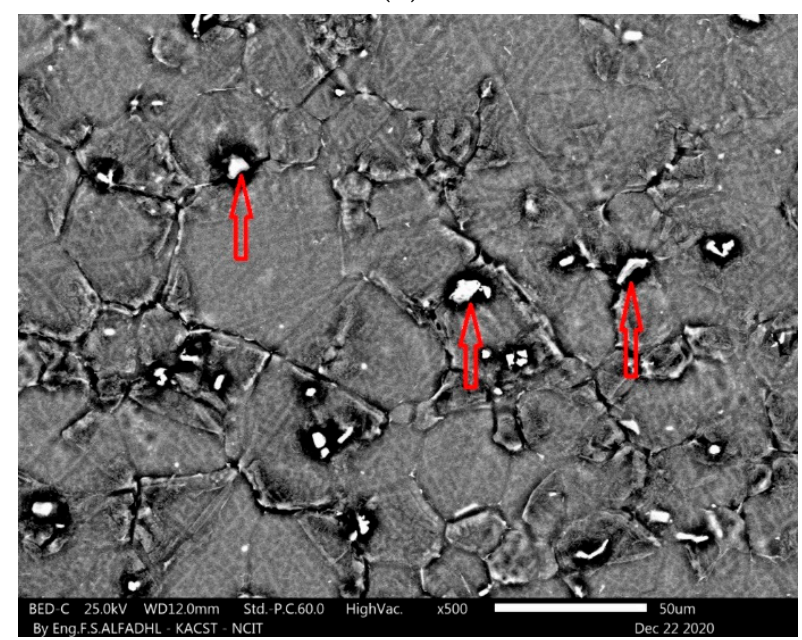

(d)

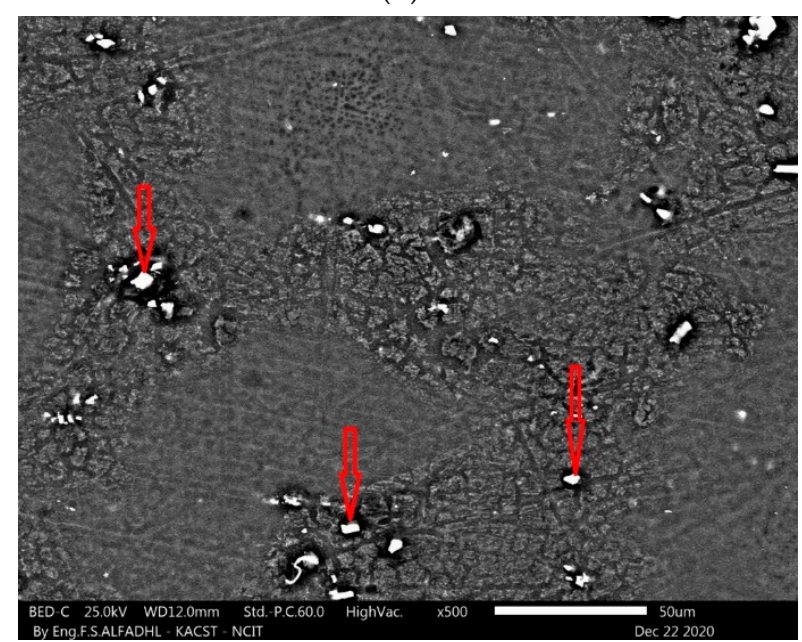

(f)

Figure 3. SEM micrographs of AZ31 alloy after ECAP processing showing the secondary phase particles as revealed in $(\mathbf{a}, \mathbf{b})$ AA, $(\mathbf{c}, \mathbf{d})$ 1-P, and $(\mathbf{e}, \mathbf{f})$ 2-B condition at $(\mathbf{a}, \mathbf{c}, \mathbf{e})$ low magnification, and $(\mathbf{b}, \mathbf{d}, \mathbf{f})$ high magnification (arrows indicate the secondary phase particles).

The 2-Bc sample's grain size distribution was not at all uniform. The sample's microstructure was characterized by having partially recrystallized regions (Figure 2f) and being highly deformed near the center (Figure 2e). Furthermore, some of the sample's 
surface had ultra-fine grain structure, while others had grains that were over a micron in diameter, as found in Figure 2e,f. This leads us to indicate that the homogeneity of the material could be drastically improved by processing the sample through a higher number of ECAP passes. Concerning the microstructure, comparing the 2-Bc-processed surfaces with the AA one shows that strain accumulation leads to drastic changes in the microstructure. 2-Bc processing results in broken and elongated un-deformed grains that are ultimately of finer grain size. These fine elongated grains were detected in central areas, which were directed in a direction parallel to that of extrusion, trailing the trace of SPD. Additionally, several twins are present within the grains, which contributed to the limited slip-system of the closed packed hexagonal structure of $\mathrm{Mg}$ (Figure 2e). However, the recrystallized regions increased in size as equiaxed ultrafine grains with an average size of $5 \mu \mathrm{m}$ were formed. The majority of the microstructure is deformed and ultra-fine in size, but some elongated un-deformed grains remain, concentrated inside the UFG region as shown in Figure 2f.

ECAP processing significantly refined the $\alpha-\mathrm{Mg}$ matrix and the secondary phase particles as seen in Figure $3 \mathrm{e}, \mathrm{f}$, and the higher the deformation, the more the distribution of particles became homogenous, as evident when comparing the 2-Bc sample with the others. Not only that but 2-Bc ECAP processing also fragmented the $\alpha$-Mg matrix and the secondary phase particles at the grain boundary thus remarkably refining them through dynamic recrystallization and severe shear deformation. The previous can be ascertained by comparing Figure $3 e, f$ to their AA counterparts: Figure $3 a, b$. The high magnification SEM images (Figure $3 b, d, f)$ indicated that the grain boundaries are concentration areas for the secondary phase with rather a few of them distributed in the grain interior. When comparing the secondary phase particles of both types of samples, it was clear that those of the AA sample were large and agglomerated, while those of the ECAP processed were fine to a high degree. Those of AA samples were also sparse as shown in Figure 3a,b, while the ECAPed secondary phases greatly precipitated in the matrix. Processing the AZ31 samples through 1-P resulted in a multitude of fine secondary phase particles with an average size ranging from 3 to $5 \mu \mathrm{m}$. The majority of these fine particles were distributed along the $\alpha-\mathrm{Mg}$ GBs, as previously mentioned and shown in Figure $3 \mathrm{c}, \mathrm{d}$. Processing via $2-\mathrm{Bc}$, and thus increasing the straining, produced some small ultra-fine secondary particles (ranging from 1 to $3 \mu \mathrm{m}$ ) that are not only homogeneously distributed along the grain boundaries of the $\alpha-\mathrm{Mg}$ matrix but also lie inside the $\alpha-\mathrm{Mg}$ grains as (Figure $3 \mathrm{e}, \mathrm{f}$.)

\subsection{Corrosion Measurement}

To investigate the effects of using ECAP processing on the corrosion behavior of AZ31 $\mathrm{Mg}$ alloy, several electrochemical tests were conducted on the AA and processed samples in ringer acetate solution. Shown in Figure 4a are the ECAP-processed samples' and the AA sample's open circuit potential (OCP) curves, which plot the variation of electrode potential against the immersion time. Notably, the three curves follow the same pattern. The steady state potentials continuously become more noble, which indicates that a stable passive layer was formed and that it develops as the more samples are immersed. The OCP values of the three samples increase rapidly to reach the steady state after nearly $1 \mathrm{~h}$. The initial rapid increase in OCP values is regarded to be caused by an oxide-protective layer that forms on the alloy surface and becomes more stable and protective as time passes. A few things could be deducted from Figure 4a. First, it is clear that the 2-Bc sample is the slowest (47 $\mathrm{min}$ ) to reach peak value. Second, the AA sample shows a slightly nobler free corrosion potential in comparison to the ECAPed ones. Finally, the 1-P and 2-Bc samples had slightly more negative $\mathrm{OCP}$ values of $-1.53 \mathrm{~V}$, whereas the AA sample displayed a more positive OCP value of $-1.516 \mathrm{~V}$. These data are in agreement with earlier studies [11,17]. However, this potential difference of $14 \mathrm{mV}$ is trivial and does not reflect the refinement revealed by SEM results. Therefore, further electrochemical investigation and testing is still needed to examine and explain the corrosion behavior of the Mg alloy. 


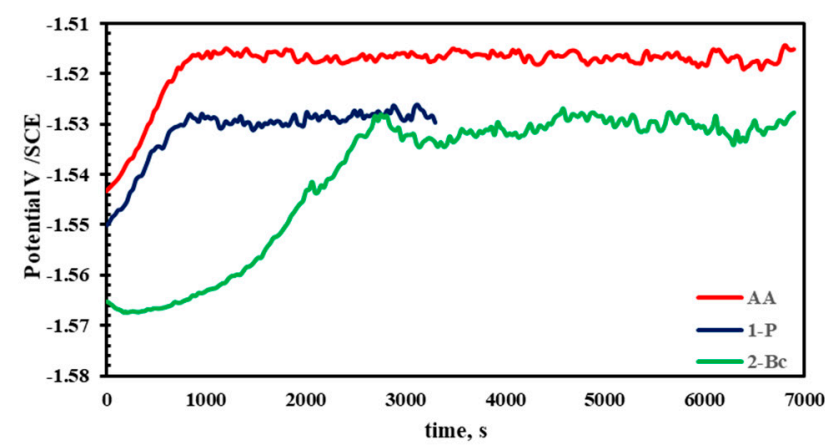

(a)

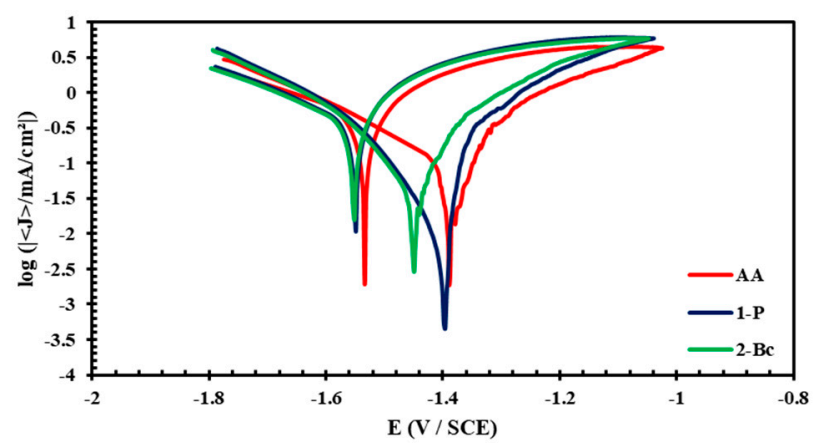

(c)

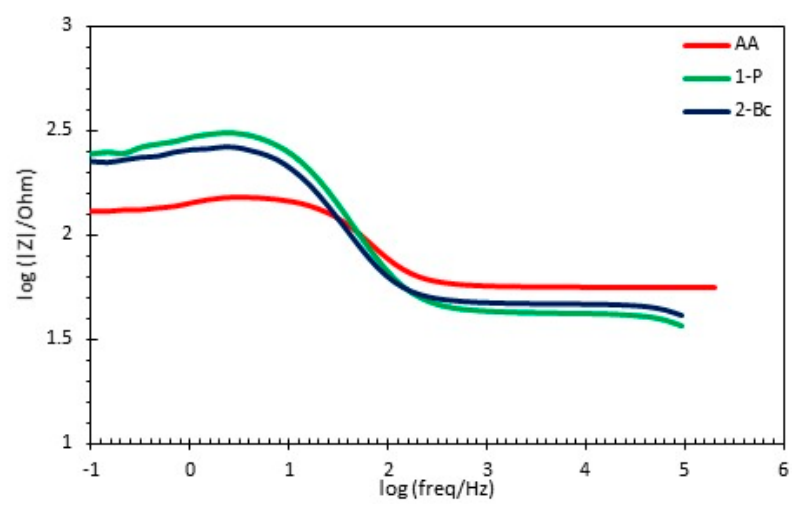

(e)

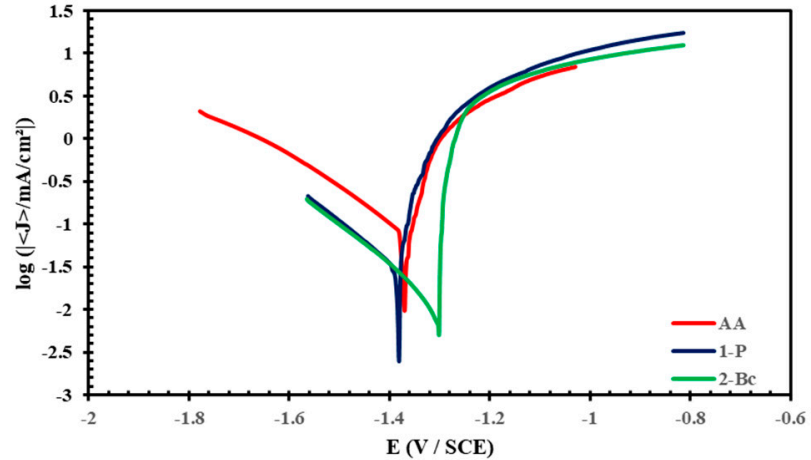

(b)

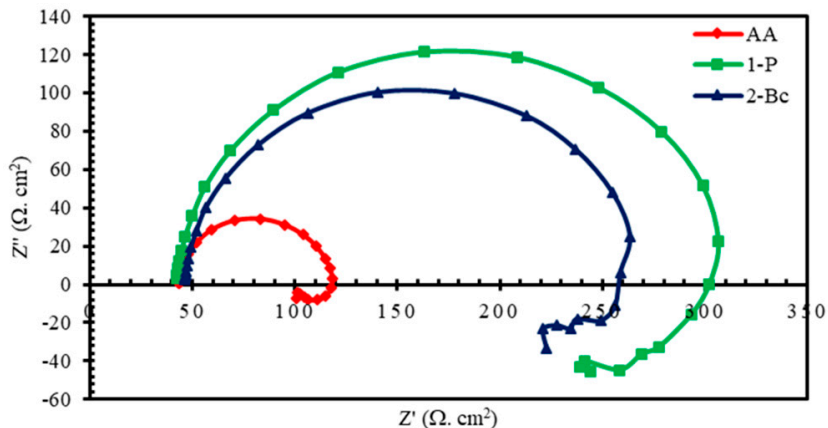

(d)

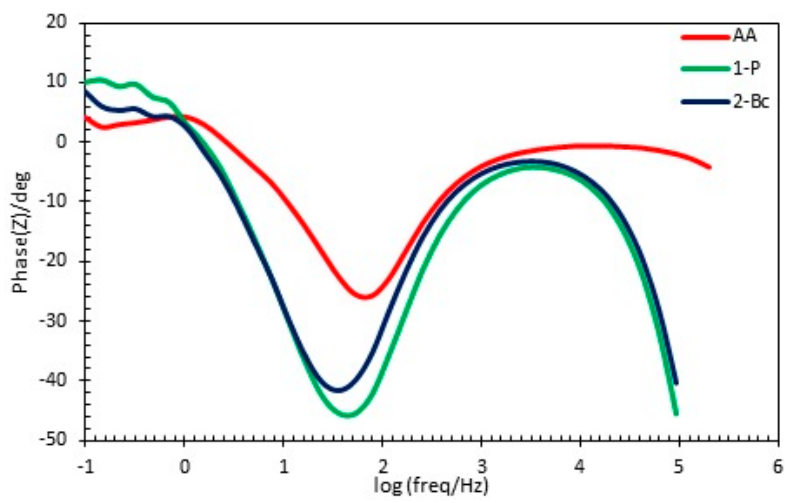

$(\mathbf{f})$

Figure 4. Corrosion measurements curves of AZ31 alloy processed through ECAP: (a) open circuit potential, (b) potentiodynamic polarization curves, (c) cyclic potentiodynamic polarization, (d) Nyquist plot, (e) electrochemical impedance diagrams (Bode plot), and (f) phase angle.

Figure $4 \mathrm{~b}$ superimposes the potentiodynamic polarization curves (Tafel plots) of the AZ31 Mg alloys before and after ECAP processing over each other. The corrosion current densities $\left(\mathrm{I}_{\text {corr }}\right)$ were extrapolated from the Tafel plots in [35]. The values of $\mathrm{I}_{\text {corr }}$, corrosion potential $\left(\mathrm{E}_{\mathrm{corr}}\right)$, Tafel anodic and cathodic constants (i.e., $\beta \mathrm{a}$ and $\beta \mathrm{c}$ ), and the corrosion rate in mils penetration per year (mpy) are listed in Table 1 . Two notes are to be made here before expanding on them later. First, ECAP-processed AZ31 billets had corrosion current densities lower than that of the AA sample, according to the polarization curves in Figure $4 \mathrm{~b}$ and as listed in Table 1. Second, the anodic and cathodic Tafel slopes varied with the number of ECAP passes applied, as listed in Table 1. 
Table 1. Electrochemical parameters obtained from potentiodynamic polarization curves of asannealed condition (AA) and processed AZ31 Mg alloys.

\begin{tabular}{|c|c|c|c|c|c|}
\hline Condition & $\begin{array}{c}\beta a \\
\left(\mathrm{mV}^{-\mathrm{dec}^{-1}}\right)\end{array}$ & $\begin{array}{c}-\beta c \\
\left(\mathrm{mV} \cdot \mathrm{dec}^{-1}\right)\end{array}$ & $\begin{array}{c}\text { Ecorr } \\
\text { (V/SCE) }\end{array}$ & $\begin{array}{c}\text { Icorr } \\
\left(\mu \mathrm{Acm}^{-2}\right)\end{array}$ & $\begin{array}{l}\text { Corrosion } \\
\text { Rate mpy }\end{array}$ \\
\hline AA & 47.3 & 224.6 & -1.361 & 88.34 & 2.63 \\
\hline 1-P & 50.1 & 204.7 & -1.382 & 22.57 & 0.85 \\
\hline $2-B c$ & 38.1 & 151.5 & -1.338 & 19.318 & 0.57 \\
\hline
\end{tabular}

Herein, $\mathrm{I}_{\text {corr }}$ provides a reliable means to estimate corrosion resistance [10,11]. In Figure $4 \mathrm{~b}$, the 1-P sample showed a significant noble shift in the Icorr compared to the AA samples when the polarization curves shifted towards lower current densities. Accordingly, with reducing the corrosion current $\mathrm{I}_{\text {corr }}$, the corrosion rate significantly decreased. Furthermore, when the number of ECAP passes increased up to 2-Bc, a further reduction in current density occurred, and accordingly led to a reduction in the corrosion rate. Thus, this confirms that more ECAP passes result in decreasing the corrosion rate. The potentiodynamic curves show that the Ecorr remains relatively unchanged after the first pass; however, the 2-Bc-processed sample showed a notable noble shift in Ecorr compared to the AA curve $(-1.3 \mathrm{~V})$. ECAPed alloys show passive-like behavior in the anodic branch, as seen in Figure $4 \mathrm{~b}$. This can confirm that an oxide film forms on the alloy surface. A significant finding was that the anodic current density is impacted by strain accumulation, this was revealed when it was significantly reduced by the shear strain accumulation in the fine-grained 2-Bc alloy compared to the coarse-grained AA alloy. This correlation leads us to infer that the anodic reaction kinetics decrease with ECAP, which is in a good agreement with [13]. Two chief post-processing microstructural factors or changes can explain the decrease in $\mathrm{I}_{\text {corr }}$, related to the decline of anodic kinetics and the passivation of Ecorr in the ECAPed alloys, i.e., grain refinement and changes in the secondary phases like their distribution, volume fraction, and morphology.

Processing the AZ31 alloy through ECAP via 1-P and 2-Bc resulted in improving the corrosion resistance by $67.7 \%$ and $78.3 \%$, respectively, compared to the AA counterpart as listed in Table 1. In general, a tendency was noticed, the current density in the Tafel plots incline towards lower values when there is an increase in the number of ECAP passes. Hence, the polarization curves observations are in a good accordance with earlier study [10]. Another related finding was that processing via ECAP mitigates the activity of galvanic corrosion, while also impeding the formation of pitting corrosion due to the refinement of grains till fine and due to the resultant uniformly distributed second phases [36]. Accordingly, this significant refinement in both $\alpha-\mathrm{Mg}$ matrix and the secondary phases coupled with the homogeneous distribution of the secondary phases after processing through multi passes of ECAP noticeably improves the corrosion rate of the ECAPed samples compared to the AA counterpart as shown in the OM and SEM findings (see Figures 2 and 3). As indicated by Table 1, ECAP profoundly affects the anodic and cathodic Tafel slopes (Ba and $\mathrm{Bc}$, respectively) with each change in the number of passes, which lies in a good agreement with [37].

Cyclic potentiodynamic polarization tests were conducted to investigate the relation between ECAP processing and the passivity of AZ31 alloy, aiming to study whether ECAP enhances passivity capabilities or not (Figure $4 c$ ). From Figure $4 c$, which superimposes the cyclic potentiodynamic plots of the AA and the ECAPed samples, it can be seen that all $\mathrm{Mg}$ alloys have common features like having a well-defined corrosion potential Ecorr that is then followed by an almost constant current density, which is a passive region, and like all anodic curves showing a passive region of $0.4 \mathrm{~V}$ with range from -1.04 to -1.44 $\mathrm{V}$. The visible passive region was formed due to an oxide film developing over the metal that acted as a barrier impeding further electrochemical reactions, which is related to the structure of the passive film. While the effect of the metal's passivity was not impacted by decreasing the grain size, the figure shows that the more processed the samples via ECAP, the lower the values of current density in the passive regions. This leads us to conclude that 
the oxide film further develops on the surface of 2-Bc sample, which agreed with previous study [37]. Figure 4c, however, indicates that the AA AZ31 alloy has an unstable passive layer, evident by the pitting that starts around the $-1.36 \mathrm{~V}$.

The $\mathrm{E}_{\mathrm{corr}}$ of the 1-P sample closely matches that of the AA sample. However, small variations in anodic curve between both shapes were observed. The $\mathrm{E}_{\mathrm{corr}}$ of the 2-Bc sample was observed to be shifted catholically relative to AA specimen by about $50 \mathrm{mV}$. In addition, the reverse sweep resulted in a positive hysteresis loop, while positive hysteresis loops were also attained for the cyclic potentiodynamic polarization curves of the ECAPed AZ31 alloy but no pitting had occurred [38,39]. It can be seen that both 1-P and 2-Bc passivate at an $\mathrm{E}_{\text {corr }}$ of $-1.55 \mathrm{~V}$ (Figure $4 \mathrm{c}$ ). It is worth to mentioning here that for all samples, the re-passivation potential $\mathrm{E}_{\text {rep }}$ is higher than the corrosion potential $\mathrm{E}_{\mathrm{corr}}$ of the forward scan. The potential difference between $\mathrm{E}_{\mathrm{corr}}$ and $\mathrm{E}_{\text {rep }}$ for 2-Bc sample, AA AZ31, and 1-P are 100,143 , and $150 \mathrm{mV}$, respectively, with the 2-Bc sample showing less potential difference, which indicates improvement against pitting corrosion.

The anti-corrosion performance of the ECAP-processed alloy was evaluated using electrochemical impedance spectroscopy (EIS). Figure 4d details the Nyquist plots of the AA alloy as well as the ECAP-processed alloy. The plots in Figure 4d shows that it is characteristic of all the $\mathrm{Mg}$ alloys to produce capacitive semicircles at intermediate-tohigh frequencies [10]. This capacitive semicircle is a result of a combination of the alloy's resistance to charge transfer and the manifestation of double-layer capacitance [37]. Herein, the analysis found that processing via ECAP gradually increases corrosion resistance performance (Figure 4d). The AA sample's plots displayed a small semicircle, whereas the ECAPed AZ31 samples showed a much larger semicircle than that of the AA counterpart (Figure $4 \mathrm{~d}$ ), which agrees with the potentiodynamic polarization results in this study and also in a previous study [32]. This indicates that the UFG sample has better corrosion resistance performance compared to the unprocessed rod. Additionally, increasing the processing passes up to 2-Bc resulted in a larger semicircle diameter compared to the 1-P rod, which indicates that a higher number of ECAP passes correlates with improved alloy corrosion resistance due to the grain refinement; this finding is in a good agreement with Sherif et al. [40]. Further inspection of Figure $4 \mathrm{~d}$ reveals that increasing the strain on the sample via ECAP processing produces a stronger oxide film, which in turn improves the anti-corrosion performance of $\mathrm{Mg}$ alloys. ECAP accomplishes this by impeding charge transfer processes through deactivating active anodic and cathodic sites [32].

The Bode impedance plots of the AA and ECAP-processed AZ31 Mg alloys are superimposed in Figure 4e. Through the inspection of the figure, it becomes apparent that at lower and moderate frequencies (up to $1.7 \mathrm{~Hz}$ ), the impedance values rise remarkably with those of the ECAP-processed samples predominating over the AA samples. It is worth mentioning here that in low frequencies, larger values of impedance indicate a better corrosion barrier [41]. The polarization resistance is extrapolated at low frequencies (log $f=0)$. At intermediate frequencies $(1.7 \mathrm{~Hz})$, the ECAPed alloys exhibit a more extended capacitance like shown in Figure 4e. In addition, the processed samples show higher phase angles (Figure 4f) in comparison to their AA counterpart, which is a sign that they exhibit a stable oxide film formed on the surface. Alongside the phase angle plots, the Bode plots in Figure 8a indicate that the corrosion in the ECAP-processed samples is less developed, meaning that ECAP provided better corrosion protection. The high impedance values of both processed samples, highlighted in Figure 4e, confirm that more ECAP processing, at higher strain values, leads to better corrosion resistance. Alongside this, increasing the processing via ECAP also increases the phase angles, as mentioned above, which leads to a more protective and improved oxide film.

To more accurately gauge and analyze the electrochemical response of the various AZ31 alloys, the EIS spectra of the samples were fitted to an electrical circuit (Figure 5). The resistance of the solution is denoted by Rs, the constant phase element (CPE1) describes the capacitance of the oxide film, and the double layer charge transfer resistance of the charge transfer process at the AZ31 alloy/solution interface is denoted by Rct. The RL 
and L denote, respectively, the pitting corrosion resistance and inductance. The capacitive CPE element is defined in terms of $n$ where $n$ is an empirical exponent that ranges from 0 to 1 . Table 2 showcases the electrical parameters of the various components of the fitted equivalent circuit based on the EIS data of the various AZ31 alloys. The Table evidently confirms that the ECAPed AZ31 alloys display much better corrosion performance than the AA ones: where the charge transfer resistance (Rct) has significantly higher values and the pitting corrosion resistance (RL) improves from 235.1 to $649.3 \Omega . \mathrm{cm}^{2}$.

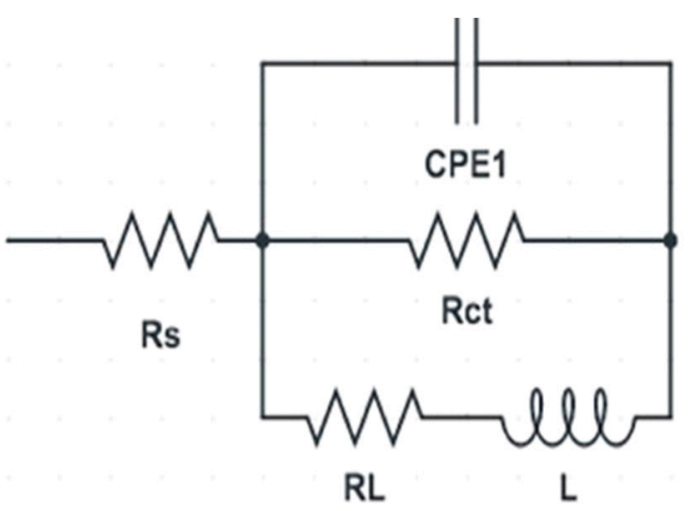

Figure 5. Equivalent circuit used to fit (EIS) data.

Table 2. Electrical parameters obtained from fitting the electrochemical impedance spectroscopy (EIS) data of the ECAPed AZ31 alloys.

\begin{tabular}{|c|c|c|c|c|c|c|}
\hline Condition & $\begin{array}{c}\text { Rs } \\
\left(\Omega \cdot \mathrm{cm}^{2}\right)\end{array}$ & $\begin{array}{c}\text { CPE1 } \\
\left(\Omega-1 \cdot \mathrm{s}^{\mathrm{n}} \cdot \mathrm{cm}^{-2}\right)\end{array}$ & n & $\begin{array}{c}\text { Rct } \\
\left(\Omega . \mathrm{cm}^{2}\right)\end{array}$ & $\begin{array}{c}\text { RL } \\
\left(\Omega \cdot \mathrm{cm}^{2}\right)\end{array}$ & $\begin{array}{c}\mathrm{L} \\
\left.\text { (H. } \mathrm{cm}^{-2}\right)\end{array}$ \\
\hline AA & 44.28 & $5.63 \times 10^{-5}$ & 1 & 72.5 & 235.1 & 109.5 \\
\hline $1-\mathrm{P}$ & 41.68 & $5.28 \times 10^{-5}$ & 0.94 & 270.1 & 508.3 & 529.4 \\
\hline $2-\mathrm{Bc}$ & 46 & $6.8 \times 10^{-5}$ & 0.94 & 224.98 & 649.3 & 435.5 \\
\hline
\end{tabular}

Many previous works have concluded that UFG significantly impact and shape the corrosion behavior of Mg alloys [42]. This was reconfirmed when it was reported that the corrosion rate in UFG Mg alloys was remarkably lower than that in their coarse-grained counterparts $[42,43]$. These reporting are in good agreement with the OM and SEM findings in this study. Gu et al. [43] reported that processing AZ31 alloy via ECAP through up to 2-passes resulted in improving the corrosion behavior of the ECAPed sample. One possible explanation posits that decreasing grain size till ultra-fine improves the protection the passive oxide layer provided through enhancing and stabilizing the uniformity and coherency already associated with fine grains [36,44]. This enhancement then leads to better protection against localized breakdown by aggressive chemical species. Additionally, another explanation for the high corrosion resistance of the ECAPed sample was found in a study conducted [13] and found that deformed grains and grain boundaries are more susceptible to corrosive environments. They posited that this was a result of the imposed strain to deform the samples in the first place, as its accumulation leads to more energy absorption, which could be easily released afterwards [45]. In this context, the low angle grain boundaries (LAGBs) in AA samples absorb the dislocations caused by ECAP and then convert into to high angle grain boundaries (HAGBs) that makes the HAGBs produced by ECAP, which as reported above have higher grain boundary energies, more vulnerable in corrosive environments $[46,47]$. Two other studies $[33,48]$, attribute the induced superior corrosion resistance in grain refined Mg alloys to the UFGs, indicating that the UFGs are the cause of rapid noble behavior and lower galvanic intensities that impact the corrosion properties of the alloys.

To a certain extent, corrosion resistance is dependent on secondary phase particles, despite their relative nobility, where its development is influenced by their distribution. 
On one hand, the precipitation of those particles in the $\alpha$-Mg matrix could create local cathodic sites [2], which might advance corrosion. However, another major factor in how they impact corrosion resistance is their distribution in the matrix. Analysis of the 2-Bcprocessed sample revealed higher grain refinement than the 1-P sample (Figures 2 and 3). Analysis also revealed a more homogenous distribution of the secondary phase particles along the grain boundaries than the AA and 1-P counterparts, which means that processing via ECAP results in a better, more homogenized distribution of alloying elements therein. A previous study indicated that ECAP processing results in finer and a better distribution of secondary phase particles in Mg alloys and, therefore, causes a better spatial distribution of these particles. All of this led to more stabilized, enhanced passive layer that ultimately resulted in the 2-Bc sample exhibiting better corrosion resistance as confirmed by [2]. In this context, Cubides et al. [13,32] examined the AZxx alloy using X-ray diffraction (XRD) and reported that the ECAPed alloy was composed of $\alpha$-Mg matrix and a secondary phase $\left(\beta-\mathrm{Mg}_{17}-\mathrm{Al}_{12}\right)$. They reported that the intensity of the $\beta-\mathrm{Mg}_{17}-\mathrm{Al}_{12}$ peaks increased with the number of ECAP passes. They also reported that the prismatic texture became stronger with the accumulation of the strain that resulted from increasing the processing passes. Indeed, these finding is in a good matching with the OM (Figure 2) and SEM (Figure 3) findings. Accordingly, the formation of high potential phases leads to the improvement of the corrosion resistance of the Mg alloy. Tang et al. [9] found that ECAP processing resulted in an increase in the peak height of the $\beta-\mathrm{Mg}_{17} \mathrm{Al}_{12}$ phase dramatically; they attributed that to the effect of ECAP in promoting the precipitation of a large number of $\mathrm{Mg}_{17} \mathrm{Al}_{12}$ particles from the $\alpha$-Mg matrix.

It is worth mentioning here that ECAP processing Mg alloys produced a multitude of energetic crystalline defect sites therein. These crystalline defects then play a role in reducing the corrosion potential of the alloy to more noble values as reported in [41-43]. This takes place due to the defects promoting the development of magnesium oxide and hydroxide $\mathrm{MgO} / \mathrm{Mg}(\mathrm{OH})_{2}$ protective films $[13,42,43]$. The $\mathrm{Mg}(\mathrm{OH})_{2}$ protective film could also be further strengthened through grain refinement, like that occurring due to ECAP processing, which stimulates its development, improving the alloy's corrosion resistance [42]. Figure 6 shows SEM micrographs of the AZ31 alloy before and after processing through ECAP coupled with the EDS spectrum, which gives the elemental composition of the AZ31 samples after corrosion tests. It could be stated that intergranular corrosion is the dominant corrosion mode in all the samples. From the magnified SEM micrographs (Figure 6a,c,e), it is clear that there are some precipitate protective layers. As seen in Figure 6, increasing the processing passes up to 2-Bc resulted in strengthening of the protective layer (as seen in Figure 6e, when compared to the AA condition seen in Figure 6a), which leads to a reduction in the corrosion rate. Accordingly, these findings agreed with the EIS findings (Figure $4 \mathrm{~d}, \mathrm{e}$ ) and a previous study [42]. Additionally, the ECAPed samples were denser and coherent in appearance compared to the AA counterpart (Figure 6e compared to Figure 6a). This morphology resulted in a more protective layer resulting in more corrosion resistance, which agreed with [13]. On the other hand, from the EDS spectrum seen in Figure 6, it is clear that the major constituent elements were found to be $\mathrm{Mg}, \mathrm{Al}, \mathrm{Zn}, \mathrm{O}, \mathrm{Cl}, \mathrm{Mn}$, and $\mathrm{Si}$. As shown in the EDS analysis, the microstructure mostly contains $\mathrm{Mg}$ and $\mathrm{O}$, which indicates the presence of the protective layer $\mathrm{Mg}(\mathrm{OH})_{2}$ [49]. Notably, the percentage of $\mathrm{Mg}, \mathrm{Al}$, and $\mathrm{Zn}$ was reduced in the processed sample compared to the AA counterpart. In addition, increasing the processing passes up to 2-Bc led to a further reduction (as seen in Figure $6 \mathrm{f}$ compared to Figure $6 \mathrm{~b}, \mathrm{~d}$ ) due to high potential phases forming. Additionally, the corrosion initiated at the grain boundaries was a consequence of microgalvanic coupling between the secondary phases and the $\alpha-\mathrm{Mg}$ matrix [32]. Furthermore, the large size of secondary phases (as seen in Figure $3 b$ ) acts as a galvanic cathode more effectively than the finer secondary phases (Figure 3f), thus accelerating the anodic dissolution of the $\alpha-\mathrm{Mg}$ matrix [32]. 


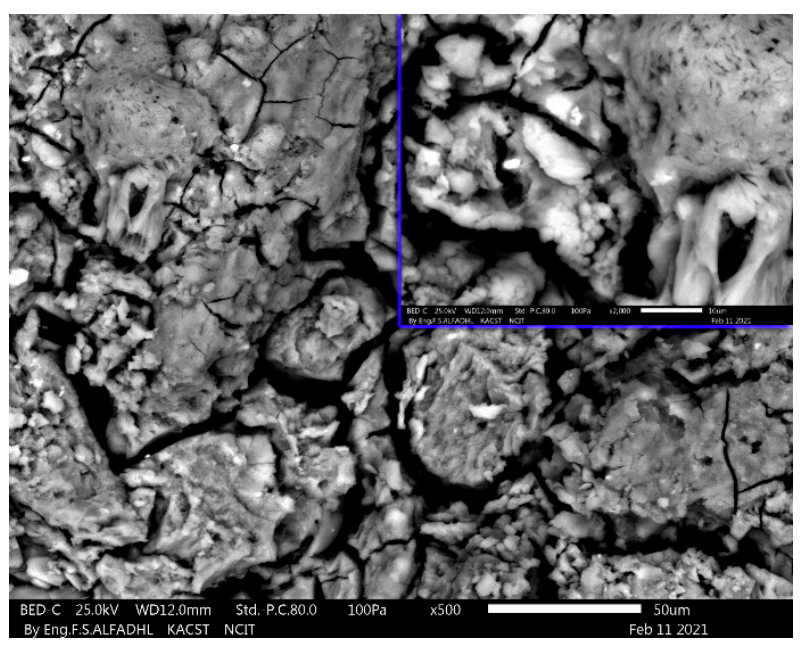

(a)

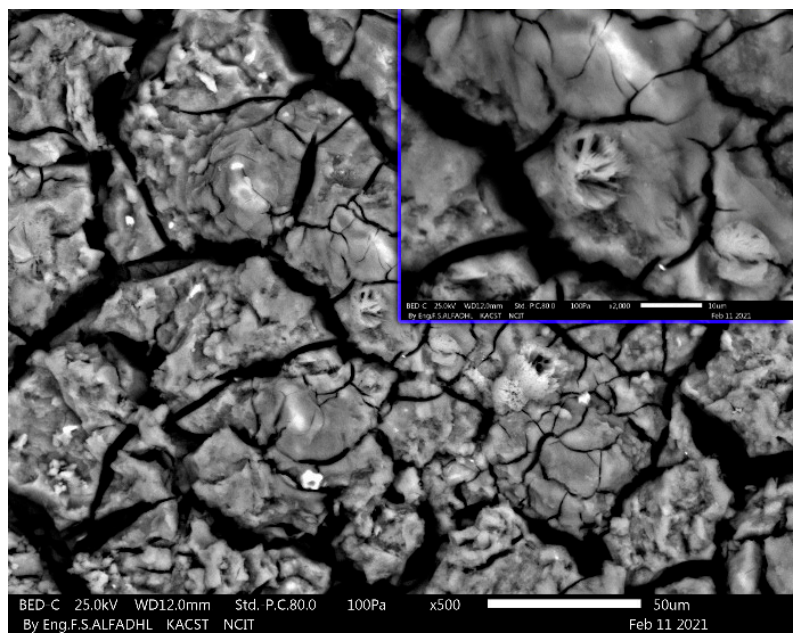

(c)

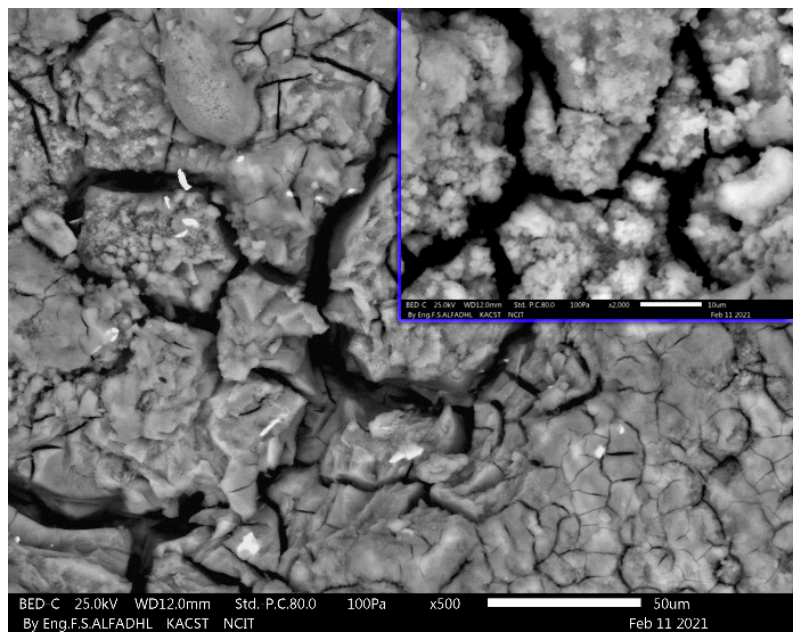

(e)

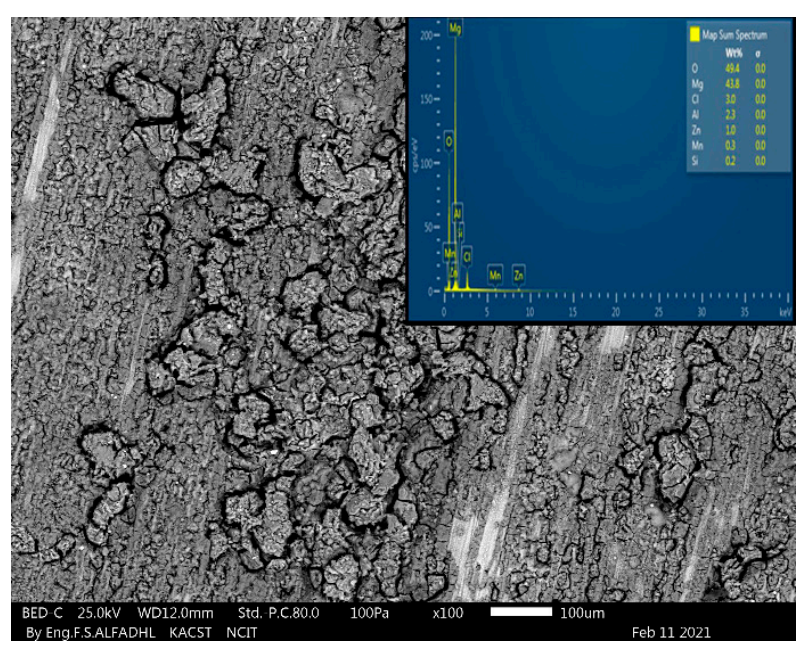

(b)

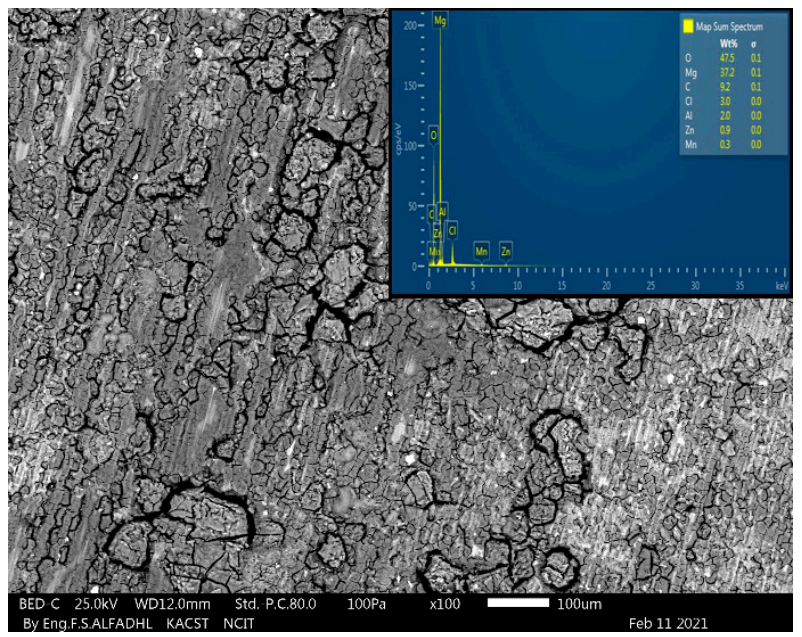

(d)

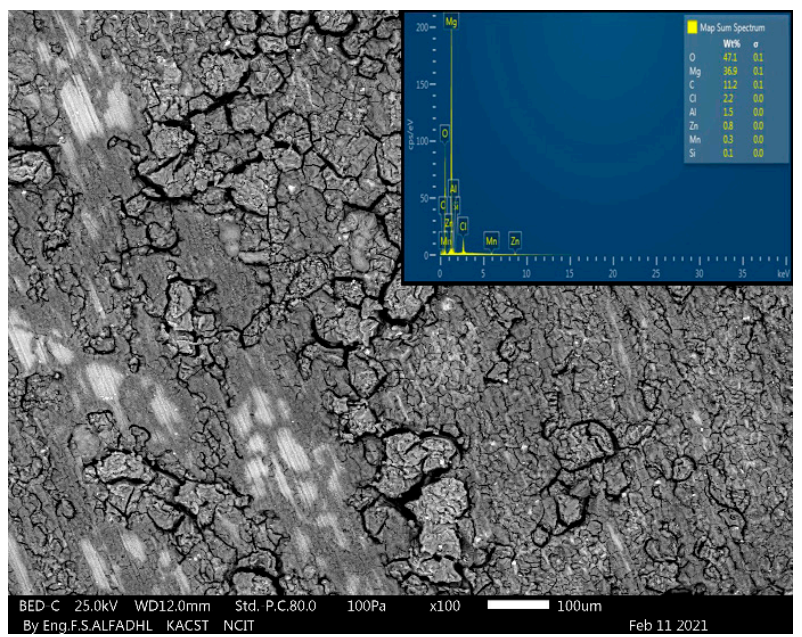

(f)

Figure 6. SEM micrographs of the AZ31 alloy after corrosion test $(\mathbf{a}, \mathbf{b})$ AA, (c,d) 1-P, and $(\mathbf{e}, \mathbf{f})$ 2-Bc at (a,c,e) high magnification and $(\mathbf{b}, \mathbf{d}, \mathbf{f})$ low magnification coupled with the EDS spectrum.

\subsection{Hardness Evolution}

The results of the Vickers microhardness test of the AZ31 extrudates have been mapped to the 3D-colored contours depicted in Figures 7 and 8, which, respectively, display the 
readings across TS and LS cross-sections. The AA sample had a uniform hardness reading of $55 \mathrm{Hv}$ all over. As concluded from the displayed 3D-colored contours, each increase in the number of passes corresponds to a general improvement of hardness readings. This increase in passes also amounts to the homogenization of the hardness readings, as the values shown tend towards more uniformity in the 2-Bc sample. From the displayed contours in Figure 7a,b, it is evident that more strain hardening had occurred at the corners compared to the central regions, as the highest $\mathrm{Hv}$ values of 103 and 126 were reported at the corners versus the lowest values of 75 and 87 that were recorded at the center regions of 1-P and 2-Bc transverse sections extrudates, respectively. The difference in the hardness values between the central and peripheral areas was due to the interaction between the billets' peripheries and the ECAP's die walls. Friction between those two entities imposed a large degree of inhomogeneous strain that would increase with any increase in the cross-section.

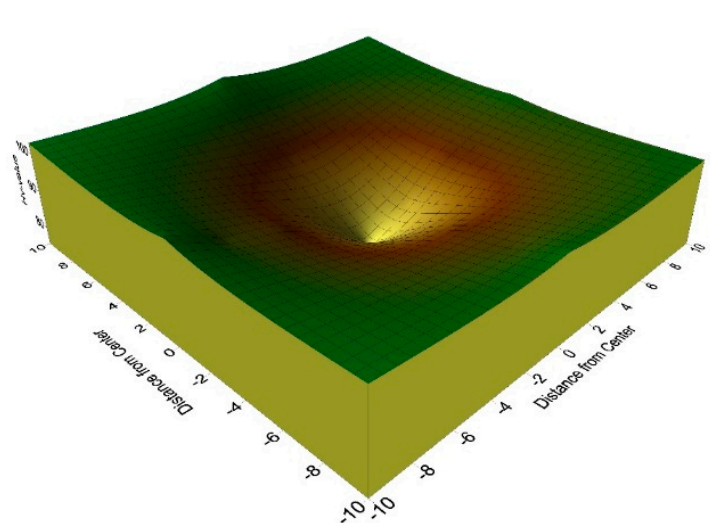

a

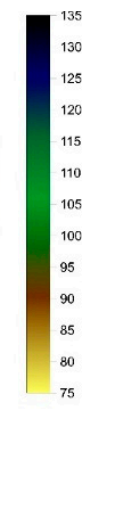

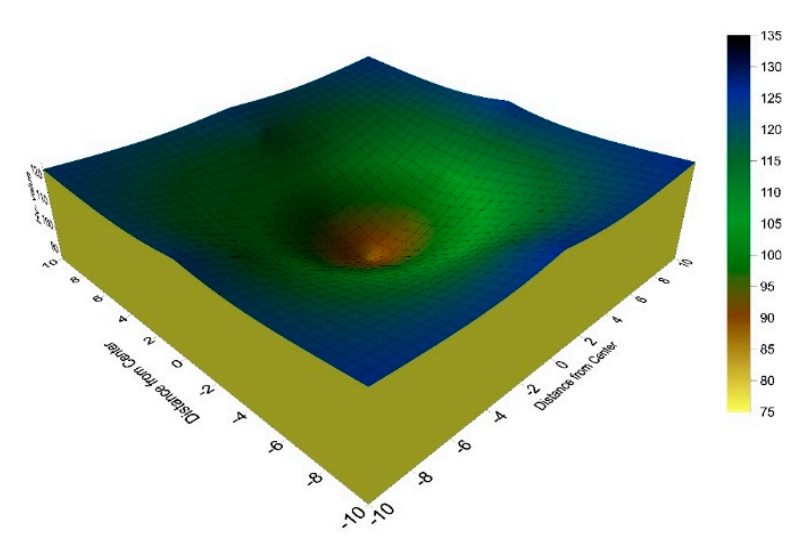

b

Figure 7. Color-coded contour maps for the Hv values recorded on the top TS of the ECAP-processed rods through (a) 1-P and (b) 2-Bc.
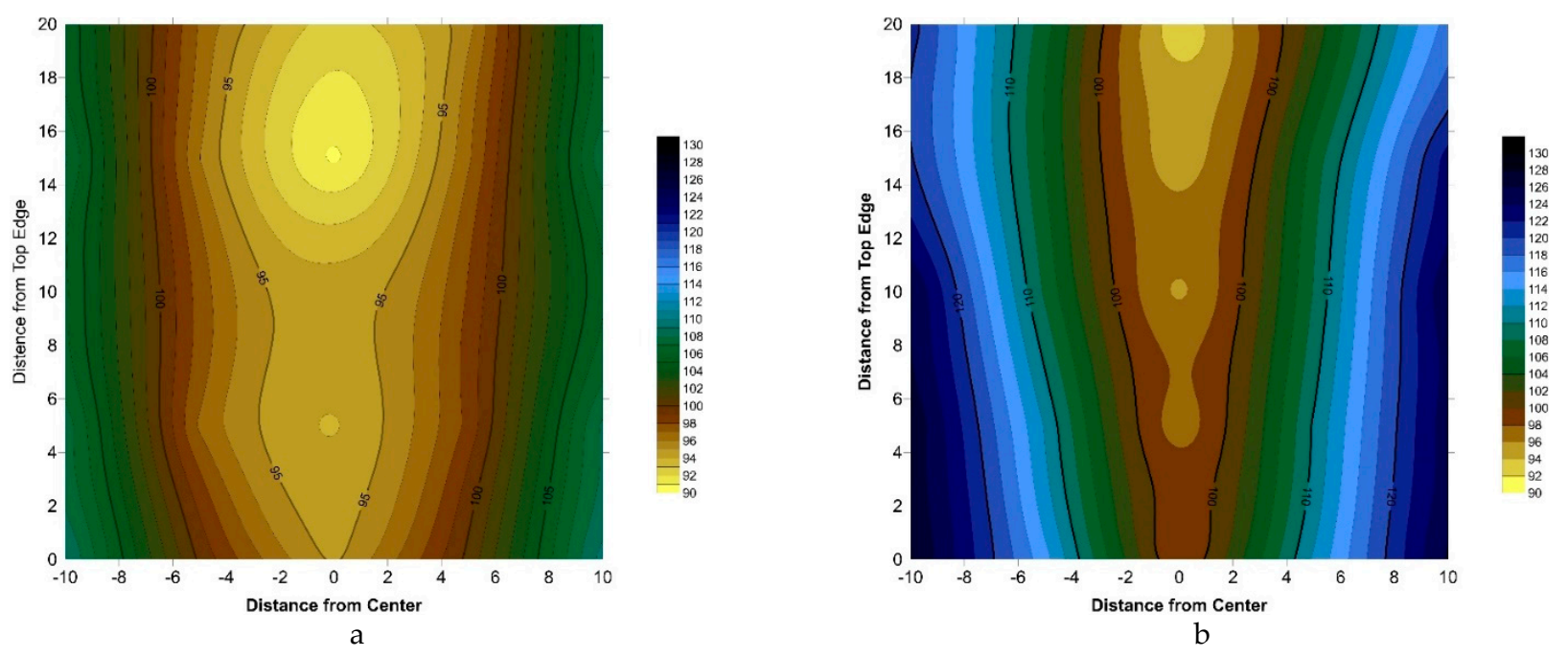

Figure 8. Color-coded contour maps for the Hv values recorded on the top LS of the ECAP processed rods through (a) 1-P and (b) 2-Bc.

Figure 8 leads us to conclude that more ECAP processing leads to an improvement in Hv values along the LS, whereas first pass processing via 1-P sample shows considerable improvement over the AA and any further processing leads to minor improvement. Furthermore, Hv value testing in the processed samples produces the lowest values near the central region, with the hardness values increasing radially. Another noticeable finding was that the upper part of the samples' LS tended to produce relatively higher hardness 
values; this occurred with both 1-P and 2-Bc samples (Figure 8a,b). The aforementioned difference in hardness values is caused by the plunge applying pressing force on the top part during processing. A gradual increase in $\mathrm{Hv}$ values occurred along the peripheries and central regions of the 1-P extrudate, with the increasing trend occurring towards the top peripheral area, as observed in Figure 8a. The maximum recorded value was $109 \mathrm{Hv}$ at the sample top peripheral zone, whereas the minimum recorded value was $92.5 \mathrm{HV}$ at the sample bottom central area. However, for the 2-Bc extrudate, the highest value of $128 \mathrm{Hv}$ was recorded alongside the peripheral region, whereas the lowest value of $94.8 \mathrm{Hv}$ was recorded at the center as demonstrated in Figure $8 \mathrm{~b}$.

As discussed before, during ECAP processing dislocation occur, multiplicate and sometimes get absorbed, causing the formation of both LAGBs and HAGBs alongside grain refinement till materials become of UFG. In this context, the UFG structure after ECAP processing is depicted in Figure 2. The evident enhancement in hardness values after ECAP processing can be attributed to the strain accumulation as the number of processing passes increased. Alongside that, the UFG structure yielded from ECAP processing inhibits dislocation glide, thus leading to far greater strength in the material, according to the HallPetch equation [50,51]. In addition, the formation of twins (Figure 2e) and accumulation of dislocations also have an effective role in the ECAPed samples [52].

\section{Conclusions}

In the current study, a detailed analysis of the effect of ECAP processing on corrosion behavior, microstructural evolution, and hardness values of the AZ31 Mg alloy was done. The corrosion behavior of the ECAPed alloy was investigated using open circuit potential, potentiodynamic polarization, cyclic potentiodynamic polarization, and electrochemical impedance spectroscopy. The Vickers hardness distribution was studied on sections cut parallel and perpendicular to the extrusion direction. The following conclusions can be drawn:

1. The microstructure of the AA sample is almost solely composed of the agglomeration of coarse equiaxed grains of the $\alpha-\mathrm{Mg}$ matrix and the secondary phase particles.

2. ECAP processing through 2-Bc resulted in a highly deformed central region with elongated grains aligned parallel to the extrusion direction.

3. The UFG recrystallized structure was mostly visible in the peripheral regions.

4. Processing via $2-\mathrm{Bc}$ resulted in the formation of some small ultra-fine secondary particles that are uniformly dispersed inside the $\alpha$-Mg grains and alongside its grain boundaries.

5. Potentiodynamic polarization curves showed that ECAP processing through 1-P and 2-Bc resulted in reducing the corrosion rate by $67.7 \%$ and $78.3 \%$, respectively, compared to the AA counterpart,

6. Analyzing the EIS results revealed that increasing the amount of ECAP processing passes correlates with improved corrosion resistance.

7. Grain refinement due to ECAP resulted in improved pitting corrosion resistance (RL).

8. ECAP processing through 2-Bc resulted in increasing the Vickers hardness values by $132 \%$ and $71.8 \%$ at the peripheral and central areas, respectively, compared to their AA counterpart.

Author Contributions: Conceptualization, A.I.A., T.A.A., M.O.A., H.A.E.-H. and W.H.E.-G.; methodology, A.I.A., H.A.E.-H. and W.H.E.-G.; validation, A.N.A., E.S.A. and R.A.; formal analysis, A.I.A., T.A.A., M.O.A. and W.H.E.-G.; investigation, A.N.A., E.S.A. and R.A.; data curation, W.H.E.-G., T.A.A. and M.O.A.; writing-original draft preparation, W.H.E.-G. and T.A.A.; writing—review and editing, B.W.E.-G.; project administration, A.I.A., H.A.E.-H. and W.H.E.-G. All authors have read and agreed to the published version of the manuscript.

Funding: This research was funded by the Deanship of Scientific Research, Qassim University. 
Data Availability Statement: All the raw data supporting the conclusion of this paper were provided by the authors.

Acknowledgments: Researchers would like to thank the Deanship of Scientific Research, Qassim University, for funding publication of this project.

Conflicts of Interest: The authors declare no conflict of interest.

\section{References}

1. Němec, M.; Jäger, A.; Tesař, K.; Gärtnerová, V. Influence of alloying element Zn on the microstructural, mechanical and corrosion properties of binary Mg-Zn alloys after severe plastic deformation. Mater. Charact. 2017, 134, 69-75. [CrossRef]

2. Minárik, P.; Král, R.; Pešička, J.; Daniš, S.; Janeček, M. Microstructure characterization of LAE442 magnesium alloy processed by extrusion and ECAP. Mater. Charact. 2016, 112, 1-10. [CrossRef]

3. Torabi, H.; Hoseini, M.; Sadrkhah, M.; Faraji, G.; Masoumi, A. Microstructure, mechanical properties and bio-corrosion properties of MgHA bionanocomposites fabricated by a novel severe plastic deformation process. Ceram. Int. 2020, 46, 2836-2844. [CrossRef]

4. Bryła, K.; Horky, J.; Krystian, M.; Dobrzyńska, L.L.; Mingler, B. Microstructure, mechanical properties, and degradation of Mg-Ag alloy after equal-channel angular pressing. Mater. Sci. Eng. C 2020, 109, 110543. [CrossRef]

5. Zhang, X.; Yuan, G.; Wang, Z. Mechanical properties and biocorrosion resistance of Mg-Nd-Zn-Zr alloy improved by cyclic extrusion and compression. Mater. Lett. 2012, 74, 128-131. [CrossRef]

6. Zhang, J.; Kang, Z.; Wang, F. Mechanical properties and biocorrosion resistance of the Mg-Gd-Nd-Zn-Zr alloy processed by equal channel angular pressing. Mater. Sci. Eng. C 2016, 68, 194-197. [CrossRef] [PubMed]

7. Mordike, B.L.; Ebert, T. Magnesium: Properties-applications-potential. Mater. Sci. Eng. A 2001, 302, 37-45. [CrossRef]

8. Jiang, J.; Zhou, Q.; Yu, J.; Ma, A.; Song, D.; Lu, F.; Zhang, F.; Yang, D.; Chen, J. Comparative analysis for corrosion resistance of micro-arc oxidation coatings on coarse-grained and ultra-fine grained AZ91D Mg alloy. Surf. Coat. Technol. 2013, 216, 259-266. [CrossRef]

9. Tang, L.; Zhao, Y.; Islamgaliev, R.K.; Tsao, C.Y.A.; Valiev, R.Z.; Lavernia, E.J.; Zhu, Y.T. Enhanced strength and ductility of AZ80 Mg alloys by spray forming and ECAP. Mater. Sci. Eng. A 2016, 670, 280-291. [CrossRef]

10. Prithivirajan, S.; Narendranath, S.; Desai, V. Analyzing the combined effect of crystallographic orientation and grain refinement on mechanical properties and corrosion behaviour of ECAPed ZE41 Mg alloy. J. Magnes. Alloys 2020, 8, 1128-1143. [CrossRef]

11. LI, X.; Jiang, J.H.; Zhao, Y.H.; Ma, A.B.; Wen, D.J.; Zhu, Y.T. Effect of equal-channel angular pressing and aging on corrosion behavior of ZK60 Mg alloy. Trans. Nonferrous Met. Soc. China 2015, 25, 3909-3920. [CrossRef]

12. Jiang, J.; Ma, A.; Saito, N.; Shen, Z.; Song, D.; Lu, F.; Nishida, Y.; Yang, D.; Lin, P. Improving Corrosion Resistance of RE-containing Magnesium Alloy ZE41A Through ECAP. J. Rare Earths 2009, 27, 848-852. [CrossRef]

13. Cubides, Y.; Karayan, A.I.; Vaughan, M.W.; Karaman, I.; Castaneda, H. Enhanced mechanical properties and corrosion resistance of a fine-grained Mg-9Al-1Zn alloy: The role of bimodal grain structure and $\beta$-Mg17Al12 precipitates. Materialia 2020, 13, 100840. [CrossRef]

14. Luo, A.A. Magnesium casting technology for structural applications. J. Magnes. Alloys 2013, 1, 2-22. [CrossRef]

15. Song, D.; Li, C.; Liang, N.; Yang, F.; Jiang, J.; Sun, J.; Wu, G.; Ma, A.; Ma, X. Simultaneously improving corrosion resistance and mechanical properties of a magnesium alloy via equal-channel angular pressing and post water annealing. Mater. Des. 2019, 166, 107621. [CrossRef]

16. Zhao, D.; Witte, F.; Lu, F.; Wang, J.; Li, J.; Qin, L. Current status on clinical applications of magnesium-based orthopaedic implants: A review from clinical translational perspective. Biomaterials 2017, 112, 287-302. [CrossRef] [PubMed]

17. Mostaed, E.; Hashempour, M.; Fabrizi, A.; Dellasega, D.; Bestetti, M.; Bonollo, F.; Vedani, M. Microstructure, texture evolution, mechanical properties and corrosion behavior of ECAP processed ZK60 magnesium alloy for biodegradable applications. J. Mech . Behav. Biomed. 2014, 37, 307-322. [CrossRef] [PubMed]

18. Almenaif, O.; Alhumaydan, Y.; Alnafisah, M.; Aldhalaan, M.; Alateyah, A.I.; El-Garaihy, W.H. A Computational Investigation into the Effect of Equal Channel Angular Processing on the Mechanical Properties of Severely Deformed ZK 60 Alloy Validated by Experiments. Am. J. Appl. Sci. 2020, 13, 296-310. [CrossRef]

19. Liu, H.; Huang, H.; Zhang, Y.; Xu, Y.; Wang, C.; Sun, J.; Jiang, J.; Ma, A.; Xue, F.; Bai, J. Evolution of Mg-Zn second phases during ECAP at different processing temperatures and its impact on mechanical properties of $\mathrm{Zn}-1.6 \mathrm{Mg}$ (wt\%) alloys. J. Alloys Compd. 2019, 811, 151987. [CrossRef]

20. Muralidhar, A.; Narendranath, S.; Nayaka, H.S. Effect of equal channel angular pressing on AZ31 wrought magnesium. J. Magnes. Alloys 2013, 1, 336-340. [CrossRef]

21. Fouad, D.M.; Moataz, A.; El-Garaihy, W.H.; Salem, H.G. Numerical and experimental analysis of multi-channel spiral twist extrusion processing of AA5083. Mater. Sci. Eng. A 2019, 764, 138216. [CrossRef]

22. Fouad, D.M.; El-Garaihy, W.H.; Ahmed, M.M.Z.; Seleman, M.M.E.; Salem, H.G. Influence of multi-channel spiral twist extrusion (MCSTE) processing on structural evolution, crystallographic texture and mechanical properties of AA1100. Mater. Sci. Eng. A 2018, 737, 166-175. [CrossRef]

23. El-Garaihy, W.H.; Fouad, D.M.; Salem, H.G. Multi-channel Spiral Twist Extrusion (MCSTE): A Novel Severe Plastic Deformation Techniquefor Grain Refinement. Metall. Mater. Trans. 2018, 49, 2854-2864. [CrossRef] 
24. Valiev, R.Z.; Langdon, T.G. Principles of equal channel angular pressing as a processing tool for grain refinement. Prog. Mater. Sci. 2006, 51, 881-981. [CrossRef]

25. Xu, B.; Sun, J.; Yang, Z.; Xiao, L.; Zhou, H.; Han, J.; Liu, H.; Wu, Y.; Yuan, Y.; Zhuo, X.; et al. Microstructure and anisotropic mechanical behavior of the high-strength and ductility AZ91 Mg alloy processed by hot extrusion and multi-pass RD-ECAP. Mater. Sci. Eng. A 2020, 780, 139191. [CrossRef]

26. Suna, J.; Xu, B.; Yang, Z.; Zhuo, X.; Han, J.; Wu, Y.; Song, D.; Liu, H.; Jiang, J.; Ma, A. Developing an industrial-scale ECAP $\mathrm{Mg}-\mathrm{Al}-\mathrm{Zn}$ alloy with multi-heterostructure for synchronously high strength and good ductility. Mater. Charact. 2020, 164, 110341. [CrossRef]

27. Cao, Y.; Ni, S.; Liao, X.Z.; Song, M.; Zhu, Y.T. Structural evolutions of metallic materials processed by severe plastic deformation. Mater. Sci. Eng. R 2018, 133, 1-59. [CrossRef]

28. Liu, H.; Ju, J.; Yang, X.W.; Yan, J.L.; Song, D.; Jiang, J.H.; Ma, A.B. A two-step dynamic recrystallization induced by LPSO phases and its impact on mechanical property of severe plastic deformation processed Mg97Y2Zn1. J. Alloys Compd. 2017, 704, 509-517. [CrossRef]

29. Torabi, H.; Faraji, G.; Masoumi, A. Processing characterization of binary Mg-Zn alloys fabricated by a new powder consolidation combined severe plastic deformation method. J. Alloys Compd. 2020, 832, 154922. [CrossRef]

30. Vaughan, M.W.; Karayan, A.I.; Srivastava, A.; Mansoora, B.; Seitz, J.M.; Eifler, R.; Karaman, I.; Castaneda, H.; Maier, H.J. The effects of severe plastic deformation on the mechanical and corrosion characteristics of a bioresorbable Mg-ZKQX6000 alloy. Mater. Sci. Eng. C 2020, 115, 111130. [CrossRef]

31. Priela, E.; Mittelman, B.; Trabelsi, N.; Cohen, Y.; Koptiar, Y. A computational investigation of equal channel angular pressing of molybdenum validated by experiments. J. Mater. Process. Technol. 2019, 264, 469-485. [CrossRef]

32. Cubides, Y.; Zhao, D.; Nash, L.; Yadav, D.; Xie, K.; Karaman, I.; Castaneda, H. Effects of dynamic recrystallization and straininduced dynamic precipitation on the corrosion behavior of partially recrystallized Mg-9Al-1Zn alloys. J. Magnes. Alloy. 2020, 8, 1016-1037. [CrossRef]

33. Peron, M.; Skaret, P.C.; Fabrizi, A.; Varone, A.; Montanari, R.; Roven, H.J.; Ferro, P.; Berto, F.; Torgersen, Y. The effect of Equal Channel Angular Pressing on the stress corrosion cracking susceptibility of AZ31 alloy in simulated body fluid. J. Mech. Behav. Biomed. 2020, 106, 103724. [CrossRef]

34. Figueiredo, R.B.; Langdon, T.G. Grain refinement and mechanical behavior of a magnesium alloy processed by ECAP. J. Mater. Sci. 2010, 45, 4827-4836. [CrossRef]

35. Aljohani, T.A.; Geesi, M.H.; Kaiba, A. Evidence for enhancement of corrosion resistance of carbon steel after exposure to high-dose gamma radiation. J. Saudi Chem. Soc. 2019, 23, 525-535. [CrossRef]

36. Orlov, D.; Ralston, K.D.; Birbilis, N.; Estrin, Y. Enhanced corrosion resistance of Mg alloy ZK60 after processing by integrated extrusion and equal channel angular pressing. Acta Mater. 2011, 59, 6176-6186. [CrossRef]

37. Sadawy, M.M.; Ghanem, M. Grain refinement of bronze alloy by equal-channel angular pressing (ECAP) and its effect on corrosion behavior. Def. Technol. 2016, 12, 316-323. [CrossRef]

38. Esmailzadeh, S.; Aliofkhazraei, M.; Sarlak, H. Interpretation of Cyclic Potentiodynamic Polarization Test Results for Study of Corrosion Behavior of Metals: A Review. Prot. Met. Phys. Chem. 2018, 54, 976-989. [CrossRef]

39. Abd El Aal, M.I.; Sadawy, M.M. Influence of ECAP as grain refinement technique on microstructure evolution, mechanical properties and corrosion behavior of pure aluminum. Trans. Nonferrous Met. Soc. China 2015, 25, 3865-3876. [CrossRef]

40. Sherif, E.M.; Soliman, M.S.; El-Danaf, E.A.; Almajid, A.A. Effect of Equal Channel Angular Pressing Passes on the Corrosion Behavior of 1050 Aluminum Alloy in Natural Seawater. Int. J. Electrochem. Sci. 2013, 8, 1103-1116.

41. Gu, Y.; Ma, A.; Jiang, J.; Li, H.; Song, D.; Wu, H.; Yuan, Y. Simultaneously improving mechanical properties and corrosion resistance of pure Ti by continuous ECAP plus short-duration annealing. Mater. Charact. 2018, 138, 38-47. [CrossRef]

42. Sunil, B.R.; Kumar, T.S.S.; Chakkingal, U.; Nandakumar, V.; Doble, M.; Prasad, V.D.; Raghunath, M. In vitro and in vivo studies of biodegradable fine grained AZ31magnesium alloy produced by equal channel angular pressing. Mater. Sci. Eng. C 2016, 59, 356-367. [CrossRef]

43. Gu, X.N.; Li, N.; Zheng, Y.F.; Kang, F.; Wang, J.T.; Ruan, L. In vitro study on equal channel angular pressing AZ31 magnesium alloy with and without back pressure. Mater. Sci. Eng. B 2011, 176, 1802-1806. [CrossRef]

44. Argade, G.R.; Panigrahi, S.K.; Mishra, R.S. Effects of grain size on the corrosion resistance of wrought magnesium alloys containing neodymium. Corros. Sci. 2012, 58, 145-151. [CrossRef]

45. Song, D.; Ma, A.B.; Jiang, J.; Lin, P.; Yang, D.; Fan, J. Corrosion behavior of equal-channel-angular-pressed pure magnesium in $\mathrm{NaCl}$ aqueous solution. Corros. Sci. 2010, 52, 481-490. [CrossRef]

46. Kim, H.K.; Kim, W.J. Microstructural instability and strength of an AZ31 Mg alloy after severe plastic deformation. Mater. Sci. Eng. A 2004, 385, 300-308. [CrossRef]

47. Birbilis, N.; Ralston, K.D.; Virtanen, S.; Fraser, H.L.; Davies, C.H.J. Grain character influences on corrosion of ECAPed pure magnesium. Corros. Eng. Sci. Technol. 2010, 45, 224-230. [CrossRef]

48. Hoog, C.; Birbilis, M.; Estrin, Y. Corrosion of pure Mg as a function of grain size and processing route. Adv. Eng. Mater. 2008, 10, 579-582. [CrossRef] 
49. Bazhenov, V.; Koltygin, A.; Komissarov, A.; Li, A.; Bautin, V.; Khasenova, R.; Anishchenko, A.; Seferyan, A.; Komissarova, A.; Estrin, Y. Gallium-containing magnesium alloy for potential use as temporary implants in osteosynthesis. J. Magnes. Alloys 2020, 8, 352-363. [CrossRef]

50. Suresh, A.; Sharma, A. Effect of equal channel angular pressing (ECAP) on the evolution of texture, microstructure and mechanical properties in the Al-Cu-Li alloy AA2195. J. Alloys Compd. 2019, 785, 972-983. [CrossRef]

51. Elhefnawey, M.; Shuai, G.L.; Li, Z.; Nemat-Alla, M.; Zhang, D.T.; Li, L. On achieving superior strength for Al-Mg-Zn alloy adopting cold ECAP. Vacuum 2020, 174, 109191. [CrossRef]

52. Zhu, C.F.; Dub, F.P.; Jiao, Q.Y.; Wang, X.M.; Chen, A.Y.; Liu, F.; Pan, D. Microstructure and strength of pure Cu with large grains processed by equal channel angular pressing. Mater. Des. 2013, 52, 23-29. [CrossRef] 